\title{
Estimating properties of unconsolidated sand-clay from spectral-induced polarization
}

\author{
Mohammad Abdul Mojid $^{1 *}$, Hiroyuki $\mathrm{Cho}^{2}$ and Hideki Miyamoto ${ }^{2}$ \\ 1Department of Irrigation and Water Management, Bangladesh Agricultural University, Mymensingh - 2202, \\ Bangladesh. \\ 2Department of Agricultural Sciences, Saga University, Saga 840-8502, Japan. \\ ${ }^{*}$ Corresponding author. Email: ma_mojid@yahoo.com
}

Copyright @ 2016 Mojid et al. This article remains permanently open access under the terms of the Creative Commons Attribution License 4.0, which permits unrestricted use, distribution, and reproduction in any medium, provided the original work is properly cited.

Received 22nd January, 2016; Accepted 26th March, 2016

\begin{abstract}
Spectral-induced polarization (SIP) of glass beads, gravel, sand and sand-clay mixtures (5, 10 and $20 \%$ clay by weight) was measured over $10 \mathrm{mHz}$ to $100 \mathrm{~Hz}$ by employing an SR810 DSP lock-in amplifier. Phase shift $(\varphi)$, and real part $\left(\sigma^{\prime}\right)$ and imaginary part $\left(\sigma^{\prime \prime}\right)$ of complex electrical conductivity of the materials were calculated from the measured voltage and its $x$ - and $y$-components to link them to physico-chemical properties of the materials. The phase shift decreased with the increase in salt concentration in pore water and diminished above a material-specific limiting salt concentration. The imaginary part of electrical conductivity was strongly correlated with clay content of the samples. For gravel and sand, $\varphi$ was strongly sensitive to pore-water content at $0.1 \mathrm{~Hz}$, and there was a material-specific correlation between $\varphi$ and pore-water content. The ratio of the real part of electrical conductivity of the unsaturated samples to that of the saturated samples increased linearly with the increasing degree of pore-water saturation (ratio of water content of a sample to its water content at saturation) except for sand $+20 \%$ clay mixture, in which the real part of electrical conductivity ratio first increased linearly and then leveled off at high $(\approx 0.6)$ water saturation. The real part of electrical conductivity ratio versus the degree of pore-water saturation relationship was different for sand $+10 \%$ clay and sand $+20 \%$ clay samples but unique for sand and sand $+5 \%$ clay samples. Such relationships of real part of electrical conductivity ratio of soils to their pore-water saturation provide prospects of predicting important soil properties such as soil salinity.
\end{abstract}

Key words: Electrical conductivity, phase shift, pore water, spectral induced polarization (SIP), soil.

\section{INTRODUCTION}

Natural soils being consisted of a number of particles of different shapes and sizes, among other variables in soils, in various orientations have made it very difficult to measure many of their properties accurately (Samouellian et al., 2005). In addition to this, the changes caused on soil by intensive agricultural activities are variable in space and time. Consequently, a continuous spatial and temporal follow-up of the soil physical and chemical properties is required. Geophysical methods can play a vital role in this regard. The general principle of geophysical methods is to study a physical property (e.g., electrical conductivity) in earth media; the study of the behavior of this property leads to the indirect and, usually, non-invasive collection of information for the earth media under investigation (Scollar et al., 1990). Among the geophysical methods, those based on the electric properties are particularly promising since soil materials and their properties (e.g., particle size distribution, mineralogy, porosity, pore size distribution, connectivity, water content, solute concentration, electrical conductivity) are strongly correlated and can be quantified through the geoelectrical properties. Indeed, the flux of electrical charges through a soil permits conductor materials like metals and electrolytes to be distinguished from insulating materials like air (Samouëlian et al., 2005). 
According to these investigators, the soil materials (soil grains) exhibit intermediate electrical properties depending on their physical and chemical properties such as texture, salinity and water content. The air medium is an insulator (i.e., infinitively resistive), the resistivity of pore water is a function of the ionic concentration, and the resistivity of the solid grains is related to the electric charge density at the surface of the constituents. All these factors affect the electrical resistivity of a soil, but in different ways and to different extents.

Electrical resistivity method is increasingly getting importance since electrical conductivity (reciprocal of resistivity) can delineate some properties (e.g., water content, salinity) of soils (Logsdon and Laird, 2004; Samouëlian et al., 2005). It is based on the fact that conduction of electricity occurs in soils by the movement of ions through the bulk saturating electrolyte and by the movement of adsorbed ions, which remain in the electrical double layers (EDLs). The inner layer of an EDL is typically negatively charged mineral surface, attracting positively charged ions contained in the pore water to form the firmly attached Stern layer (Stern, 1924; Leroy and Revil, 2004). Beyond the Stern layer, positively charged ions continue to be attracted by the negatively charged mineral surface, but, at the same time, are repelled by each other and, also, by the Stern layer. The resulting dynamic equilibrium is referred to as the diffuse layer and represents the transition zone between the Stern layer and the neutral part of the pore water. The purpose of electrical resistivity surveys is to determine resistivity distribution of the sounding soil volume. For this, artificially generated electric currents are supplied to the soil and the resulting potential differences are measured. The patterns of potential difference provide information on the form of sub-surface heterogeneities and of their electrical properties (Kearey et al., 2013). The greater the electrical contrast between the soil matrix and heterogeneity, the easier is the detection. Consequently, the electrical resistivity of a soil can be considered as a proxy for the variability of soil physical properties (Banton et al., 1997). It is, however, noted that the electrical resistivity methods cannot measure the movement of adsorbed ions in the EDLs. The movement of adsorbed ions is measured only with induced polarization (IP) and spectral-induced polarization (SIP) methods.

The real part of the complex electrical conductivity of a soil is frequency independent below $1 \mathrm{kHz}$ while the imaginary part is frequency dependent; both the real and imaginary parts are dependent on soil-water content (Ulrich and Slater, 2004). So, the variation of these electrical conductivities with water content may contain information about porosity, texture, pore geometry and, hence, water transmission properties (e.g., hydraulic conductivity) of the soil, and the properties of the pore water (Knight and Endres, 1990;
Boadu and Seabrook, 2000). Electrical conductivity, although depends on porosity and tortuosity, among other factors like type of soil minerals present, porewater electrical conductivity and pore-water content (Revil, 1999; Binley and Kemna, 2005), is, however, less sensitive to detect small concentration of toxic contaminants (Olhoeft, 1985; SEG, 1990; Sumner, 2012). Induced polarization, IP, on the other hand, is more sensitive than electrical conductivity to the interfacial properties of rocks and soils (Lesmes and Frye, 2001). In IP method, an electric current is induced into the materials to be investigated through two electrodes, called current electrodes, and voltage is monitored through two other electrodes, called potential electrodes. IP methods are of two types: time domain and frequency domain. Time domain IP methods measure the voltage decay over a specified time interval after the induced voltage is removed; the integrated voltage is used as the measurement. Frequency domain IP methods use alternating currents (ac) to induce electric charges into the materials, and the apparent resistivity is measured at different ac frequencies. Spectral induced polarization, SIP, is an extension of the IP method; it measures frequencydependent (spectral) complex impedance, which is equivalent to the amount of resistance and phase shift between the electric current and voltage. IP methods have shown some good prospects for mapping subsurface contamination in cases where direct current (dc) resistivity methods are ineffective (Sadowski, 1988; Cahyna et al., 1990; Börner et al., 1993). Polarization in soils and sediments is caused by charged mineral surfaces and constrictions in the pore space, which lead to zones of unequal ionic transport properties in the pore space (Börner et al., 1996; Leroy et al., 2008). Several investigators (Börner et al., 1996; Sturrock, 1999; Binley et al., 2005; Kemna et al., 2005; Tong et al., 2006; Zisser et al., 2010) found good correlations between IP parameters and hydraulic properties of subsurface formations. It is not possible to extract information on the variations in porosity (controlling factor on electrolytic conduction) and grain size (controlling factor on surface conduction) from a single resistivity measurement. But, IP data can be acquired in conjunction with resistivity measurements using time- or frequency-domain IP instrumentation. The IP measurements directly sense the polarization of the mineral-fluid interface and are primarily related to the surface electrical conductivity and surface area of the interconnected pore network (Weller et al., 2015). Electric models to describe IP data have evolved to use a complex surface electrical conductivity term, where the real part of the surface electrical conductivity represents electro-migration of charges along the mineral-fluid interface and the imaginary part represents the polarization of charges at the mineral-fluid interface (Vinegar and Waxman, 1984; Lesmes and Frye, 2001; Revil and Florsch, 2010). 
The polarization response of non-metallic minerals has potential in engineering and environmental applications (Olhoeft, 1985; Vanhala and Soininen, 1995; Börner et al., 1996). The dependency of polarization upon lithological composition and hydrological properties of soils and rocks has raised the prospect of applying the SIP method in hydro-geological and engineering-geologic investigations (Binley et al., 2005; Hördt et al., 2007; Grunat et al., 2013). The SIP parameters were found to be dependent on the surface charge density, surface ionic mobility, particle size distribution, porosity, pore-water content, pore-water salinity and temperature of the soils (Ogilvy and Kuzmina, 1972; de Lima and Sharma, 1992; Revil et al., 2012; Weller et al., 2015). A number of previous studies demonstrated strong relationships between (i) the imaginary part of electrical conductivity and surface electrical conductivity (Vinegar and Waxman, 1984; Börner et al., 1996; Revil, 2012; Weller et al., 2013) and (ii) the imaginary part of electrical conductivity and surface area normalized to the pore volume (Börner et al., 1996; Weller et al., 2010b; Revil, 2012). By using simplified relations between the imaginary and real parts of the spectral electrical response, Börner et al. (1996), Weller and Börner (1996), Hördt et al. (2007), and Attwa and Günther (2013) predicted hydraulic conductivity of aquifers. Waxman and Smits (1968) showed a positive correlation between the cation exchange capacity (CEC) of sand and imaginary part of electrical conductivity, and Vinegar and Waxman (1984) proposed a linear relation between these two soil properties. Similar positive relation between soil CEC and low-frequency polarization was also reported by other researchers (e.g. Slater and Lesmes, 2002; Revil and Florsch, 2010; Revil, 2013). By analyzing 114 samples from 10 independent data sets, Weller et al. (2010b) showed linear relation between the imaginary part of electrical conductivity and ratio of surface area to pore volume.

Leroy and Revil (2009), Weller and Slater (2012) and Revil (2013) found dependency of low-frequency imaginary part of electrical conductivity of clay-sand mixtures on their specific surface area and surface charge density or alternatively on their CEC. Okay et al. (2014) reported steadily increasing real and imaginary parts of electrical conductivity of clay-sand mixtures with clay content of the mixtures. These investigators also found the imaginary part fairly independent of the pore fluid salinity but proportional to the CEC of the clay-sand mixtures. Cosenza et al. (2008) and Ghorbani et al. (2009), however, reported poor correlations between polarization and CEC for clayey rock. In most of the studies mentioned here, the surface electric charge of the soil was considered to be solely related to the mineral fraction of the solid phase and mostly to the clay content. Schwartz and Furman (2015), however, showed that natural organic matter (OM), despite its high CEC, reduced soil polarization and that the contribution of OM to the total CEC of soil was of great importance. The relationships between the characteristics of SIP response, and lithological and pedological parameters, such as grain size distribution (Lesmes and Morgan, 2001), pore size distribution (Scott and Barker, 2003), specific surface area (Börner et al., 1996; Slater and Lesmes, 2002), presence of clay minerals (Klein and Sill, 1982; Slater and Lesmes, 2002) and permeability (Börner et al., 1996; Binley et al., 2005; Revil and Florsch, 2010) were investigated in several studies. Most of these studies were, however, conducted on fully saturated samples. From the SIP measurements on variably saturated sand-clay mixtures, Breede et al. (2012) indicated that the polarization processes were plausibly related to pore sizes and not to grain sizes.

The SIP method, although increasingly becoming popular for geophysicists as a non-invasive geophysical method, has yet to be familiarized to soil scientists and other agricultural scientists. Texture, water content, salinity, pollutant content and hydraulic conductivity are some of the important soil properties with which various agricultural scientists are always concerned. Noninvasive real-time measurement of these soil properties are important for many practical applications such as irrigation scheduling, calculating leaching requirements, planning land reclamation, managing saline soils and determining land suitability for crop production. The SIP methods have potential to provide such measurements. But, accurate estimate of the soil properties from the SIP parameters relies on good understanding of the physico-chemical processes that control the SIP response of soils and of correlations between the SIP parameters and soil properties. This study therefore evaluated the SIP parameters of variably saturated glass beads, gravels, sand, clay, and sand-clay mixtures for estimating some physico-chemical properties of these materials.

\section{Theoretical background}

Induced polarization is related to ion diffusion produced by an electric current flowing through porous media. Due to the flow of electric current, gradients in ion concentration are produced in the regions where interfaces between solid and liquid phases are curved (Fixman, 1980), such as in pore constrictions. The ion concentration gradients, in turn, give rise to ion flows, which represent secondary electric currents within the pores (Marshall and Madden, 1959). These electric currents give rise to the secondary voltage, which is the manifestation of IP. When an alternating electric field is applied to a wet soil, the electrical double layers coating the soil grains are polarized (Schwarz, 1962; Leroy et al., 2008). The important part of polarization occurs in the Stern layer, usually over $1 \mathrm{mHz}$ to $100 \mathrm{~Hz}$ of the 
applied electric field (Revil and Florsch, 2010), and corresponds to the electrochemical polarization of the medium. Indeed, Koch et al. (2011), based on strong evidence, suggested that the most important processes associated with the observed SIP response take place in the Stern layer. The polarization of the Stern layer leads to a frequency-dependent dielectric permittivity and phase shift. The other main polarization process is the Maxwell-Wagner polarization, which is associated with accumulation of electrical charges in the pore space of the soil, and usually occurs above $10 \mathrm{~Hz}$ (Chen and Or, 2006). The electrochemical and Maxwell-Wagner polarization mechanisms superimpose together and result in an overall polarization in a soil below $100 \mathrm{~Hz}$ of the applied electric field.

The frequency-domain IP measurements consist of imposing a harmonic current, $I(A)$, into a material at a given frequency and measuring the resulting electric potential difference, $V(\mathrm{~V})$, between two non-polarizing voltage electrodes. The impedance, $Z^{*}(\omega)(\Omega)$, is expressed by (Okay et al., 2014).

$Z^{*}(\omega)=\frac{V}{I}=\left|Z^{*}(\omega)\right| e^{i \varphi(\omega)}$

where $\omega$ is the angular frequency $\left(\operatorname{rad~s}^{-1} ; \omega=2 \pi f\right.$ with $f$ being the frequency in $\mathrm{Hz}$ or $\left.\mathrm{s}^{-1}\right), i(=\sqrt{-1})$ is the imaginary unit and $\varphi$ is the phase shift (rad). The complex resistivity $\rho^{*}(\omega)(\Omega \mathrm{m})$ is related to $Z^{*}(\omega)$ by a geometric factor $K(\mathrm{~m})$ as

$\rho^{*}(\omega)=K Z^{*}(\omega)$

The geometric factor, $K$, takes into account the position of the electrodes, size and shape of the samples, and the boundary conditions on their surface. The complex electrical conductivity, $\sigma^{*}(\omega)\left(\mathrm{S} \mathrm{m}^{-1}\right)$, of the material can be expressed in polar form by (Weller et al., 1996; Breede et al., 2012; Koch et al., 2012; Okay et al., 2014)

$\sigma^{*}(\omega)=\frac{1}{\rho^{*}(\omega)}=\sigma^{\prime}(\omega)+i \sigma^{\prime \prime}(\omega)$

where $\sigma^{\prime}(\omega)$ is the real part and $\sigma^{\prime \prime}(\omega)$ is the imaginary part of the complex electrical conductivity (both in $S$ $\mathrm{m}^{-1}$ ), respectively. The real part, which is the in-phase component and corresponds to the intrinsic electrical conductivity, is related to porosity, tortuosity, pore fluid electrical conductivity and pore-fluid saturation (Revil, 1999). The imaginary part, which is the quadrature component, corresponds to polarization effects of the Stern layer. The phase angle, caused by polarization, that defines phase shift, $\varphi$, between the injected current signal and the measured voltage, is expressed by (Weller et al., 1996; Breede et al., 2012; Okay et al., 2014)

$\varphi(\omega)=\tan ^{-1}\left(\frac{\sigma^{\prime \prime}(\omega)}{\sigma^{\prime}(\omega)}\right) \approx \frac{\sigma^{\prime \prime}(\omega)}{\sigma^{\prime}(\omega)}$
In Equation 4, $\tan ^{-1}\left(\sigma^{\prime \prime}(\omega) / \sigma^{\prime}(\omega)\right) \approx \sigma^{\prime \prime}(\omega) / \sigma^{\prime}(\omega)$ remains valid for small values of $\varphi(<100 \mathrm{mrad}$; Okay et al., 2014) obtained at low frequency $\left(10^{-3}\right.$ to $10^{3} \mathrm{~Hz}$; Koch et al., 2012; Weller et al., 2015), where IP phenomena are typically measured in the field.

\section{MATERIALS AND METHODS}

\section{Materials}

\section{Glass beads, gravel, sand and sand-clay}

Eight experiments were done using glass beads, gravels, sand, clay and three sand-clay mixtures with 5 , 10 and $20 \%$ (by weight) clay content. Table 1 records some details of these materials with a summary of experimental conditions. Quartz sand used in the samples had a median grain size of $0.23 \mathrm{~mm}$ and a specific surface area of $0.101 \mathrm{~m}^{2} \mathrm{~g}^{-1}$. The clay (actual clay content of $0.77 \mathrm{~kg} \mathrm{~kg}^{-1}$ ) was smectite dominated and contained, predominantly, sodium cations. The other elements of the clay mineralogy were kaolinite, vermiculite, mica, chlorite, quartz and feldspar. The CEC of the clay was 48.5 meq per $100 \mathrm{~g}$ and the specific surface was $305 \mathrm{~m}^{2} \mathrm{~g}^{-1}$.

\section{Sample holder}

The sample holder (Figure 1) consisted of a transparent acrylic cylinder; $13 \mathrm{~cm}$ long, $6 \mathrm{~cm}$ inner diameter and $6.8 \mathrm{~cm}$ outer diameter; with both ends open. An acrylic ring; $1 \mathrm{~cm}$ thick, $6 \mathrm{~cm}$ inner diameter and $10 \mathrm{~cm}$ outer diameter; was fitted at both ends so that the total length of the sample holder was $15 \mathrm{~cm}$. Two $2.5-\mathrm{cm}$ thick acrylic plates of $6.8 \mathrm{~cm}$ diameter were used as end caps to close the ends of the sample holder. The inner side of the end caps was depressed to accommodate a current electrode plate inside it. Two porous bronze plates, with $6 \mathrm{~cm}$ diameter, $3.1 \mathrm{~mm}$ thickness and 15 $\mu \mathrm{m}$ effective pore diameter, were used as current electrodes; the bronze plates formed the upper and lower boundaries of the sample volume. Koch et al. (2011) also used similar bronze plates as current electrodes. The end cap and the lower ring could be fixed with six plastic screws. There were two small holes on each end cap: one hole was used for the passage of a thin electric cable to connect the current electrode with the current source, and the other hole was used as the passage for water and/or salt solution into and out of the sample holder. Both holes could be closed with cork screws. There were two other holes, both of diameter $8 \mathrm{~mm}$, on the sample holder that were fitted with a $2.5-\mathrm{cm}$ long glass tubes. The holes, $7 \mathrm{~cm}$ apart and $4 \mathrm{~cm}$ away from the ends, were used to insert potential electrodes. As found by Zimmermann et al. (2008), this positioning of the potential electrodes on 
Table 1. Composition of the samples and conditions of the experiments in two different groups. Note that the water contents at different steps of group 2 were controlled manually by draining the samples. Sometimes, after several saturation steps, water could not be drained out easily. So, it was not possible to keep the number of saturation steps equal for different solution concentrations of the samples.

\begin{tabular}{|c|c|c|c|c|c|c|c|}
\hline $\begin{array}{c}\text { Group } \\
\text { no. }\end{array}$ & $\begin{array}{l}\text { Expt. } \\
\text { no. }\end{array}$ & $\begin{array}{l}\text { Sample } \\
\text { material }\end{array}$ & $\begin{array}{c}\text { Grain diameter } \\
(\mathrm{mm})\end{array}$ & $\begin{array}{l}\text { Dry bulk density } \\
\qquad\left(\mathrm{g} \mathrm{cm}^{-3}\right)\end{array}$ & $\begin{array}{c}\text { Porosity } \\
(\%)\end{array}$ & $\begin{array}{l}\text { Solution conc. } \\
\left(\mathrm{mol} \mathrm{L}^{-1}\right)\end{array}$ & $\begin{array}{l}\text { Pore-water content }{ }^{b} / \\
\text { measurement step }\end{array}$ \\
\hline \multirow{6}{*}{1} & 1 & $\begin{array}{l}\text { glass } \\
\text { beads }\end{array}$ & 6.00 & - & - & $\mathrm{C}_{1}-\mathrm{C}_{12}{ }^{\mathrm{a}}$ & saturated \\
\hline & 2 & gravel & $2.00-3.00$ & 1.62 & 39 & $\begin{array}{l}\mathrm{C}_{1}, \mathrm{C}_{2}, \mathrm{C}_{5}, \mathrm{C}_{6} \\
\mathrm{C}_{8}, \mathrm{C}_{9}, \mathrm{C}_{10}, \mathrm{C}_{12}\end{array}$ & saturated \\
\hline & 3 & sand & 0.23 & 1.59 & 40 & $\begin{array}{l}\mathrm{C}_{1}, \mathrm{C}_{2}, \mathrm{C}_{5}, \mathrm{C}_{6}, \\
\mathrm{C}_{8}, \mathrm{C}_{9}, \mathrm{C}_{11}, \mathrm{C}_{12}\end{array}$ & saturated \\
\hline & 4 & clay & $(0.16-0.73) \times 10^{-3}$ & 1.14 & 57 & $\begin{array}{l}\mathrm{C}_{1}, \mathrm{C}_{2}, \mathrm{C}_{5}, \mathrm{C}_{6} \\
\mathrm{C}_{8}, \mathrm{C}_{9}, \mathrm{C}_{11}, \mathrm{C}_{12}\end{array}$ & saturated \\
\hline & 1 & sand & 0.23 & 1.59 & 40 & $\mathrm{C}_{1}, \mathrm{C}_{2}, \mathrm{C}_{5}, \mathrm{C}_{6}$ & 4-7 steps \\
\hline & 2 & $\begin{array}{l}\text { sand }+ \\
5 \% \text { clay }\end{array}$ & $\begin{array}{l}\text { sand-clay } \\
\text { mixture }\end{array}$ & 1.78 & 33 & $\mathrm{C}_{1}, \mathrm{C}_{5}, \mathrm{C}_{6}, \mathrm{C}_{9}$ & 5-7 steps \\
\hline \multirow[t]{2}{*}{2} & 3 & $\begin{array}{l}\text { sand }+ \\
10 \% \text { clay }\end{array}$ & $\begin{array}{l}\text { sand-clay } \\
\text { mixture }\end{array}$ & 1.83 & 31 & $\mathrm{C}_{1}, \mathrm{C}_{2}, \mathrm{C}_{5}, \mathrm{C}_{8}$ & 6 steps \\
\hline & 4 & $\begin{array}{c}\text { sand }+ \\
20 \% \text { clay }\end{array}$ & $\begin{array}{l}\text { sand-clay } \\
\text { mixture }\end{array}$ & 1.91 & 28 & $\mathrm{C}_{1}, \mathrm{C}_{2}, \mathrm{C}_{5}, \mathrm{C}_{8}$ & 5-6 steps \\
\hline
\end{tabular}

${ }^{\mathrm{a}} \mathrm{C}_{1}: 0.0001, \mathrm{C}_{2}: 0.001, \mathrm{C}_{3}: 0.002, \mathrm{C}_{4}: 0.003, \mathrm{C}_{5}: 0.005, \mathrm{C}_{6}: 0.01, \mathrm{C}_{7}: 0.02, \mathrm{C}_{8}: 0.05, \mathrm{C}_{9}: 0.1, \mathrm{C}_{10}: 0.2, \mathrm{C}_{11}: 0.5, \mathrm{C}_{12}: 1.0$ (The corresponding electrical conductivities are: $0.11,0.17,0.27,0.40,0.73,1.39,2.80,6.68,11.90,22.64,51.69$ and $96.52 \mathrm{dS} \mathrm{m}^{-1}$ ) b sand: $0.33,0.32,0.29,0.24,0.19$; sand $+5 \%$ clay: $0.32,0.27,0.22,0.17,0.15,0.09$; sand $+10 \%$ clay: $0.32,0.27,0.22,0.17$, $0.15,0.13$; sand $+20 \%$ clay: $0.32,0.27,0.22,0.17,0.15$ (The clay content in the samples refers to its percentage of weight of the samples).

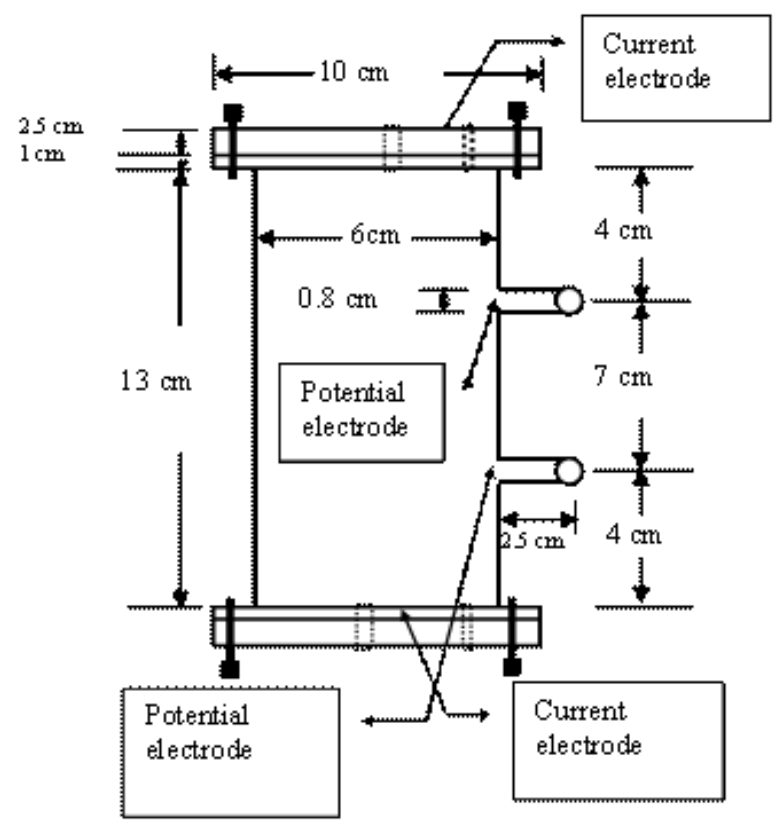

Figure 1. Schematic diagram of a sample holder for SIP measurement in laboratory.

the sample holder avoided common mode errors. Two platinum rods, each $1.5 \mathrm{~cm}$ long and $2 \mathrm{~mm}$ in diameter, were used for potential electrodes.

\section{SIP measurement system with a lock-in amplifier}

The spectral-induced polarization technique generally involves measurement of the magnitude and phase shift (or the components from which they can be calculated) of the polarization voltage (relative to a reference voltage) that results from the injection of an ac into a sample. The applied current polarizes the sample and induces polarization voltage. In this study, an SR810 DSP lock-in amplifier (Stanford Research Systems, Inc., USA) was employed as the signal source as well as the measurement unit for a frequency-domain SIP method. As described by Mojid et al. (2012; their Figure 2), the lock-in amplifier excited the sample by a sinusoidal wave from its SINE OUT port through a pair of current electrodes. The two input terminals of the lock-in amplifier received electrical response from the samples through two potential electrodes. A known current (with a current to voltage ratio of $1 \mathrm{~mA}: 1 \mathrm{~V}$ ) was applied to the samples. It is noted that, with the SR810 DSP lockin amplifier, it is possible to apply a selected current to a sample for any given current to voltage ratio, which depends on the resistance of the sample. The voltage response in the two potential electrodes was fed to the input terminals of the lock-in amplifier through two pre- 
amplifiers without gain. The high input impedance of the pre-amplifiers prevented current leakage (Vanhala and Soininen, 1995) and minimized polarization of the potential electrodes. The low output impedance of the pre-amplifiers reduced capacitive coupling effects in the cables. The amplitude of voltage and its $x$ (real)- and $y$ (imaginary)-components over the samples of different experiments were measured by the lock-in amplifier over the frequency range from $10 \mathrm{mHz}$ to $100 \mathrm{kHz}$. Considering the accuracy of our measurement system (described below), the results of this study were reported for the frequency range from $10 \mathrm{mHz}$ to 100 $\mathrm{Hz}$. The phase shift as well as the real and imaginary parts of electrical conductivity was calculated from the measured voltages.

\section{Accuracy of the SIP measurement system}

The performance of the SIP measurement system/ experimental set-up was evaluated by conducting a benchmark test. This test also provided the measurement uncertainties with the system. The sample holder-electrodes arrangement for measuring SIP was tested by employing the SR810 DSP lock-in amplifier and the results were reported, in detail, by Mojid et al. (2012); only a brief summary is presented here. Mojid et al. (2012) calibrated the SIP measurement system with known resistors, and tested it for a resistive-capacitive circuit, which closely simulated a soil sample in terms of its electrical properties. The system imparted negligible influence of capacitive coupling below $100 \mathrm{~Hz}$ frequency of the applied electric field, and provided voltage phase, $\varphi$, within 1-mrad accuracy; the noise level in the measurement was the least below $10 \mathrm{~Hz}$. An input current density of $0.35 \mathrm{~A} \mathrm{~m}^{-2}$ induced negligible noise in the measured $\varphi$ and, consequently, was found optimum for application of the method (Mojid et al., 2012).

The sample holder-electrodes configuration was evaluated by measuring amplitude of electrical conductivity and phase spectra of $0.001,0.01$ and 0.1 $\mathrm{mol} \mathrm{L}^{-1} \mathrm{KCL}$ solutions. The potential electrodes were kept only within the side tubes of the sample holder by just touching the sample material in the column to minimize polarization of the electrodes by keeping them outside of the electric field associated with the current electrodes. The electrical connection to the potential electrodes was naturally provided through the conducting pore fluid, which wetted the sample into the cylinder (Zimmermann et al., 2008) and also through the soil mineral. Filling the sample holder with a $\mathrm{KCl}$ solution, a suitable current, based on solution resistivity, to get an appreciable magnitude of voltage was applied through the current electrodes from the lock-in amplifier. The employed lock-in amplifier displayed the in-phase (along $x$-axis) and quadrature (along $y$-axis) compo- nents of the voltage along with voltage amplitude between the two potential electrodes. This voltage amplitude and its $x$ - and $y$-components were recorded over $10 \mathrm{mHz}$ to $100 \mathrm{kHz}$. As reported by Mojid et al. (2012), the effect of capacitive coupling of the cables of our SIP measurement system was negligible below 100 $\mathrm{Hz}$, but it increased monotonously at higher frequency. Also, considering the frequency range of interest for field IP data sets (Ulrich and Slater, 2004; Weller et al., 2010a; Koch et al., 2012; Weller et al., 2015), this study, however, reported SIP results over $10 \mathrm{mHz}$ to $100 \mathrm{~Hz}$. The geometric factor of the sample-electrodes arrangement, $K$ (Equation 2) was determined from the ratio of resistivity of the solutions and amplitudes of impedance. The phase error, defined by the difference between the measured and calculated phase spectra was determined for the solutions. The expected (theoretical) phase spectra in the solutions were calculated from the ratio of the imaginary part $\left(\varepsilon_{r} \varepsilon_{0} \omega\right)$ to the real part $\left(\sigma_{0}\right)$ of their conductivity amplitudes. The conductivity amplitude is expressed by $\sigma(\omega)=\sigma \circ+i \varepsilon r \varepsilon \circ \omega$, in which $\sigma_{0}$ is the dc electrical conductivity of the solution that was measured by a conductivity meter, $\varepsilon_{\mathrm{r}}$ is the dielectric constant of the solution at the temperature of measurement, $\varepsilon_{0}$ is the dielectric permittivity of free space $\left(8.85 \times 10^{-12} \mathrm{~F} \mathrm{~m}^{-1}\right), i$ is the imaginary unit $(=\sqrt{-1})$, and $\omega$ is the angular frequency $\left(\mathrm{rad} \mathrm{s}^{-1} ; \omega=2 \pi f\right.$ with $f$ being the frequency in $\mathrm{Hz}$ ).

Figure 2 illustrates the amplitude and phase spectra of $0.001 \mathrm{~mol} \mathrm{~L}^{-1} \mathrm{KCl}$ solution for the sample holderelectrodes configuration over $10 \mathrm{mHz}$ to $100 \mathrm{~Hz}$. The impedance first decreased with increasing frequency up to $0.1 \mathrm{~Hz}$ and then increased slightly before it leveled off at $100 \mathrm{~Hz}$; the cause of the increase was not clear to us. The measured phase showed a low peak of -0.18 mrad at $10 \mathrm{~Hz}$. The cause of this was not clear to us. However, the measured phase closely approximated the expected phase with a small noise that ranged from 0 to $-0.18 \mathrm{mrad}$. Such a small error in $\varphi$, obtained with the bronze-platinum electrodes combination, implied that this is a suitable sample holder-electrodes configuration for our SIP measurement method by employing the lock-in amplifier.

\section{Methods}

\section{Scheme of experiments}

The experiments were classified into two groups, each consisting of four experiments. The first group of experiments with glass beads, gravel, sand and clay were designed to evaluate the effects of frequency of the applied voltage and salt concentration of pore-water on the phase shift, and real and imaginary parts of electrical conductivity of these materials. Although 


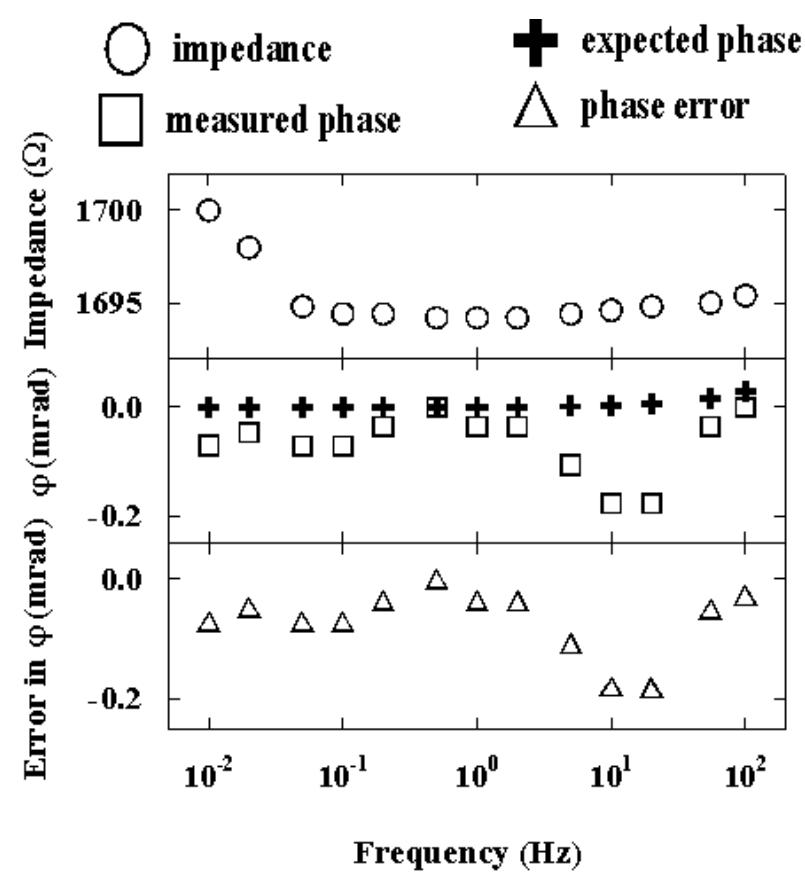

Figure 2. Impedance spectra, measured phase spectra, expected phase spectra and error in phase measurement in $0.001 \mathrm{~mol} \mathrm{~L}^{-1} \mathrm{KCl}$ solution with current electrodes of Bronze in combination with potential electrodes of platinum

sodium chloride $(\mathrm{NaCl})$ solution was used in wetting the samples for SIP measurements in most of the previous studies, we used potassium chloride $(\mathrm{KCl})$ solutions of different concentrations (Table 1) to wet the samples in our SIP measurements. Due to very specific radius of $\mathrm{K}$-ions, the CECs of the samples wetted with $\mathrm{KCl}$ solutions might be different than the CECs of the samples wetted with $\mathrm{NaCl}$ solutions in the previous studies. So, the use of $\mathrm{KCl}$ solutions instead of $\mathrm{NaCl}$ solutions was a limitation for a better comparison of our results with previous studies. In the second group, one experiment was with sand and the rest three were with sand-clay mixtures. $\mathrm{KCl}$ solutions of four different concentrations (Table 1) were used to wet the sample in each experiment. The pore-water content of the samples was varied in four to seven steps for each salt concentration of the wetting solution. The water content of the samples was varied by draining out some water at the end of each step by applying suction at the bottom by a hanging water column. It was difficult to maintain equal number of equidistant steps for each salt concentration, and we thought that it would not be a major problem in analyzing our data and presenting the results. Therefore, the number of steps varied for most of the salt concentrations. The purposes of these experiments were to evaluate the effects of salt concentration in pore water, clay content and porewater content on the SIP parameters. The details of sample preparation and their conditioning are given later under sample preparation.

\section{Sample preparation}

The glass beads, gravels and sand listed in Table 1 were washed separately with sufficient quantity of distilled water (electrical conductivity $=1.36 \times 10^{-3} \mathrm{dS}$ $\mathrm{m}^{-1}$ ) in polyvinyl chloride (PVC) columns to remove their background salts and other washable impurities. Note that, in geophysics, the commonly used unit for electrical conductivity is either $\mu \mathrm{S} \mathrm{m}^{-1}$ or $S \mathrm{~m}^{-1}$, but, in soil science, electrical conductivity is a widely used measure of soil salinity, which is expressed in $\mathrm{dS}^{-1}$. So, in this study electrical conductivity of different samples (both soil and solution) was expressed in dS $\mathrm{m}^{-1}$. The washed materials were air-dried in laboratory. Samples were prepared for different experiments (Table 1) by taking adequate quantities of the dry materials so that each sample could completely fill the sample holder. Each sample was mixed thoroughly by manual means to make it as much as a homogeneous mixture. Closing one end of the sample holder with a current electrode and an end cap (Figure 1), it was filled with the sample by incrementally packing same mass of material in approximately $4.25 \mathrm{~cm}$ layers. The sample materials were transferred into the sample holder with a spoon. The sample was compacted by applying same number of approximately identical pressure strokes at each filling step with a flat-tipped wooden rod, which was of nearly the same diameter as the interior of the sample holder. In between each filling step of the sample, the formed upper layer of the material was broken by using a sharp knife edge. Also, after each filling step, the sample holder was shaken vertically on its lower end. The open end of the sample holder was then closed with another current electrode and end cap. Two potential electrodes were inserted in the glass tubes of the sample holder by keeping their ends just within the tubes, but touching the sample in the column, and kept fixed by using plastic screws. At this stage, the sample holder was again given a few mild vertical shakes on both ends. We assumed that this procedure of sample preparation made the samples approximately homogeneous. However, the homogeneity of the samples by any sort of measurements was not checked. Koch et al. (2011) obtained consistent phase spectra through repeated measurements in sand with very small random errors when elapsed time between the measurements was small. Long elapsed time may affect SIP measurements since the SIP readings are affected by temperature, carbon dioxide levels, and any reactions occurring inside the sample. Over $1-10 \mathrm{mHz}$ frequency range, Koch et al. (2012) found inconsistent phase spectra through repeated measurements in sand, likely, due to inherently very long measurement times 
associated with the low end of the SIP frequency spectrum. The frequency range in the SIP measurements was above this range. However, no identical set of measurements was repeated, but the same sample column for different pore-water contents and concentrations in a particular experiment was used. Keeping the sample holder (with the sample inside) vertical with a stand and clamp, it was saturated slowly by passing the intended $\mathrm{KCl}$ solution through the hole at the bottom by a peristaltic pump for 24 hours. Closing the holes on the end caps, the sample was kept undisturbed for the next 24 hours to attain uniform distribution of the salt solution throughout. From the experience it is assumed that wetting the samples by slow upward flow of the solution maximized saturation level of the samples. However, some air bubbles might be entrapped in the samples. Ustra et al. (2012) and Personna et al. (2013) reported time dependence of SIP measurements following sample preparation. In their investigations, clay samples containing toluene took significant time to reach an equilibrium electrical response; for the state of electrical equilibrium after 40 days, they did not notice any clay-salt solution reaction kinetics trending towards equilibrium. So, during the 24hour incubation period for the samples, chemical equilibrium was not most possibly attained, but a physical homogeneity in salt distribution in the sample might occur.

For the first group of experiments, after the measurement of SIP data (will be described in the next section), the major part of salt solution was drained out from the samples by opening the holes on the two end caps and by applying suction through the lower hole with a hanging water column and, finally, with a hand pump. The next solution was passed through the samples as before until the new solution had completely displaced the old one that was verified by intermittent measurement of electrical conductivity of the exiting solution and comparing it to the applying solution. After attaining homogeneous distribution of salt solution in the samples in the 24-hour incubation period, the required SIP data were measured. Following the same procedure, data were recorded for saturating solutions of different concentrations as indicated in Table 1. For the second group of experiments, the SIP data were measured for four to seven pore-water contents of the samples for each $\mathrm{KCl}$ solutions. First, the SIP data were measured in the saturated samples conditioned as before. Then, removing some pore water from the samples by applying suction, they were kept undisturbed for 72 hours to attain uniform distribution of the remaining pore water before next measurements were done. The remaining water in the samples was measured by weighing them on a balance. During redistribution of solution, the sample holder was always kept horizontal and rotated, intermittently, along its longitudinal axis in order to avoid accumulation of pore water at the lower part of the sample. Although not

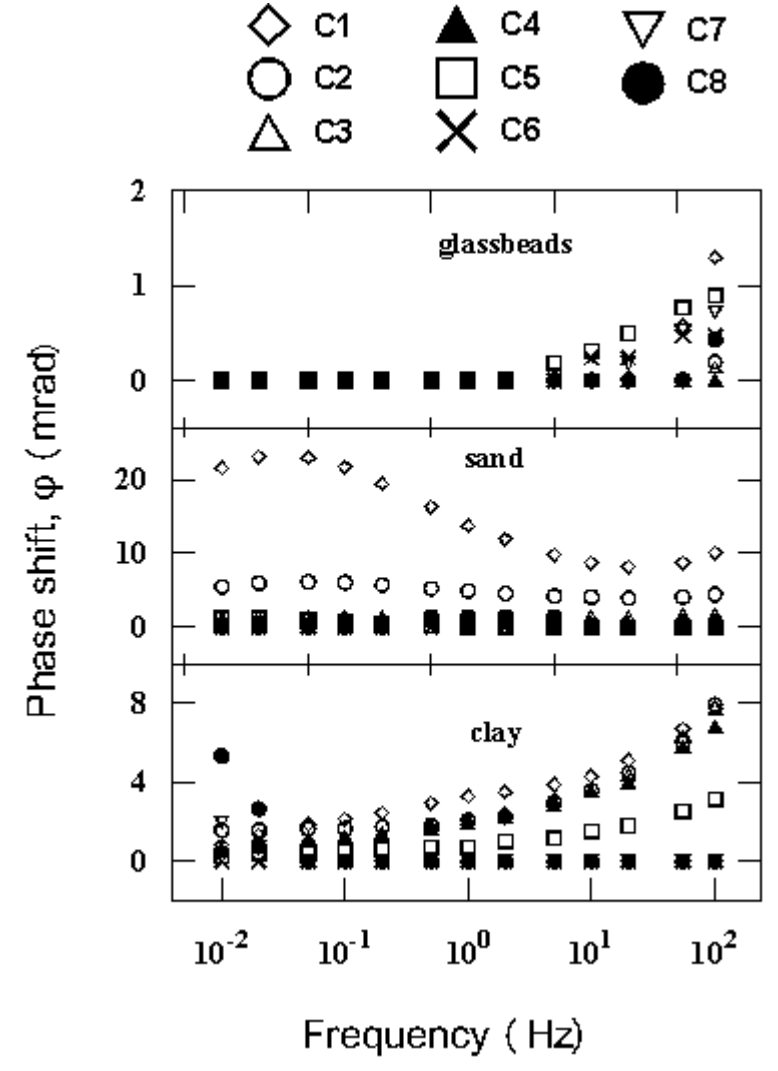

Figure 3(a). Variation of phase shift with frequency $(0.01-100 \mathrm{~Hz})$ of the applied voltage in glass beads, sand and clay for different pore-water salt concentrations under saturated condition.

verified, considering the salt concentration of pore water (Table 1) in the samples, it was presumed that the salt would not move preferentially by gravity. Following this procedure, the SIP data were measured for four to seven pore-water contents of the samples. It was noted that the sample preparation and conditioning, and all measurements were done in laboratory at $25 \pm 1^{\circ} \mathrm{C}$. At the end of each experiment, the sample was oven-dried to obtain the water content. This information was combined with the measured water outflow to obtain the water content of the sample at different steps.

\section{RESULTS AND DISCUSSION}

\section{Effects of frequency and pore-water concentration on SIP parameters}

Figure 3a illustrates variation of phase shift, $\varphi$ (Equation $4)$, observed in glass beads, sand and clay over 10 $\mathrm{mHz}$ to $100 \mathrm{~Hz}$ for different salt concentrations of pore water. Because of considerable capacitive coupling effects of the cables of our SIP measurement system above $100 \mathrm{~Hz}$ (Mojid et al., 2012), the SIP results were 
limited to this frequency range. The frequency range normally used for laboratory SIP measurements by other investigators was $0.1-10 \mathrm{~Hz}$ (Ulrich and Slater, 2004), $1-100 \mathrm{~Hz}$ (Koch et al., 2012) and $1 \mathrm{mHz}$ to 1 kHz (Kemna et al., 2012; Weller et al., 2015). However, for field IP data measurements, the usable frequencies are usually restricted to $<10 \mathrm{~Hz}$ due to excessive electromagnetic coupling at higher frequencies (Weller et al., 2010a). The variation of phase shift was different for different materials; $\varphi$ was 0 to $1.3 \mathrm{mrad}$ for glass beads, 0 to $23 \mathrm{mrad}$ for sand and 0 to $8 \mathrm{mrad}$ for clay. For any particular material, $\varphi$ was attributed to the variation of pore-water salt concentration. The phase shift is a ratio of capacitive to conductive properties of materials and was influenced by the frequency of the applied electric field. Glass beads are exclusively inert insulating dielectrics with electrical conductivity and dielectric permittivity independent of frequency at their dry state. The phase shift in glass beads was negligible below $10 \mathrm{~Hz}$. The small $\varphi$ obtained above $10 \mathrm{~Hz}$ resulted mainly from polarization of the saline pore water (Maxwell-Wagner polarization) and generally decreased with the increasing salt concentration of pore water. Like glass beads, sand is also an almost inert insulating dielectric. The phase shift in sand decreased with the increase in pore-water salt concentration. For the lowest salt concentration $\left(\mathrm{C}_{1}\right)$ in pore water, sand provided 10 to $21 \mathrm{mrad}$ phase shift over the considered frequency range (Figure 3a) having a decreasing trend with increasing frequency. A similar nature of variation of $\varphi$ over frequency was also obtained at different porewater contents in sand (discussed later). But, there was an inconsistency in the magnitude of the phase shifts for the two low concentrations $\left(C_{1}\right.$ and $\left.C_{2}\right)$ of pore water. The unsaturated sand provided considerably lower phase shift than the saturated sand, the source of this discrepancy was not however clear. As depicted in Figure $3 a, \varphi$ decreased with the increase in pore-water salt concentration up to $0.005 \mathrm{~mol} \mathrm{~L}^{-1}\left(\mathrm{C}_{5}\right)$, after which $\varphi$ diminished at higher concentrations. The polarizations of EDLs coating the soil particles and of pore water superimposed, and resulted in the phase shift in clay that had power-law dependence on frequency. Slater et al. (2006) also reported similar dependence of $\varphi$ on frequency for kaolinite-sand mixtures. Below $20 \mathrm{~Hz}, \varphi$ decreased linearly with the increase in salt concentration of pore water and effectively diminished above $0.005 \mathrm{~mol} \mathrm{~L}^{-1}$. There was an exception to this trend with $\mathrm{C}_{7}$ and $\mathrm{C}_{8}$ for which $\varphi$ increased again strongly with decreasing frequency over 0.01 to $0.02 \mathrm{~Hz}$. These results were due to the fact that the surface electrical conduction of clay particles increased with the increase in ionic strength of pore water (Revil and Glover, 1997) up to a limiting high concentration that was specific to a material. The surface electrical conduction then decreased with further increase in ionic strength of pore water because of close packing of the counter ions on the mineral surface at high salinity. The maximum surface electrical conductivity was attributed to a trade-off between the increasing surface charge density and decreasing surface ionic mobility with the increase in ionic strength of pore water. The Maxwell-Wagner polarization that represents blocking of ions at dielectric boundary layers in porous media might also play a role in the variation of phase shift in the upper part of the frequency range under consideration. The phase shift for clay over higher frequencies, especially above $100 \mathrm{~Hz}$, is attributed, along with Maxwell-Wagner polarization, to the very small pore sizes in the clay (Breede et al., 2012). Actually, induced polarization arises from the superposition of various types of polarization mechanisms, which overlap in the frequency domain (Olhoeft, 1985; Cosenza et al., 2008; Leroy et al., 2008; Leroy and Revil, 2009; Jougnot et al., 2010). In metalfree and bacteria-free porous media, three main mechanisms control induced polarization: polarization of the Stern layer coating the soil mineral, MaxwellWagner polarization and membrane polarization. The polarization of the Stern layer arises in a wide frequency range from $1 \mathrm{mHz}$ to $100 \mathrm{~Hz}$ and is controlled by the pore size distribution (Revil et al., 2012) while the Maxwell-Wagner polarization occurs at higher frequencies, usually above $10 \mathrm{~Hz}$ (Chen and Or, 2006), and is controlled by the formation factor, surface electrical conductivity and dielectric properties of different phases. Following Leroy et al. (2008), this study considered only the polarization of Stern layer assuming that electrochemical polarization of the Stern layer is the main polarization mechanism in the frequency band from $1 \mathrm{mHz}$ to $10 \mathrm{~Hz}$.

The polarization of glass beads, sand and clay was evaluated by the imaginary part of their electrical conductivity, $\sigma^{\prime \prime}$, which was generated due to surface electrical conduction of these materials. Both the surface electrical conductivity and pore-water electrical conductivity contributed to the real part of electrical conductivity, $\sigma^{\prime}$. However, the glass beads and sand being almost inert had negligible surface electrical conductivity and hence exerted negligible contribution to $\sigma^{\prime}$. The electrolytic conduction in pore water primarily controlled the conductive component of current making the surface electrical conductivity a negligible contributor. As delineated in Figure 3b, the real part of electrical conductivity thus remained practically frequency independent below $100 \mathrm{~Hz}$ for the three materials; it increased, in a few cases, only by $<2 \%$ over this frequency range. Lesmes and Frye (2001) also reported similar nature of $\sigma^{\prime}$ with frequency for Berea sandstone saturated with $\mathrm{NaCl}$ solution of concentration $0.1 \mathrm{~mol} \mathrm{~L}^{-1}$ and $\mathrm{pH} 8$.

In accordance with Equation 4, the trends of variation of the imaginary part of electrical conductivity (Figure $3 b), \sigma^{\prime \prime}$, and phase shift (Figure $3 a$ ) of the materials with 


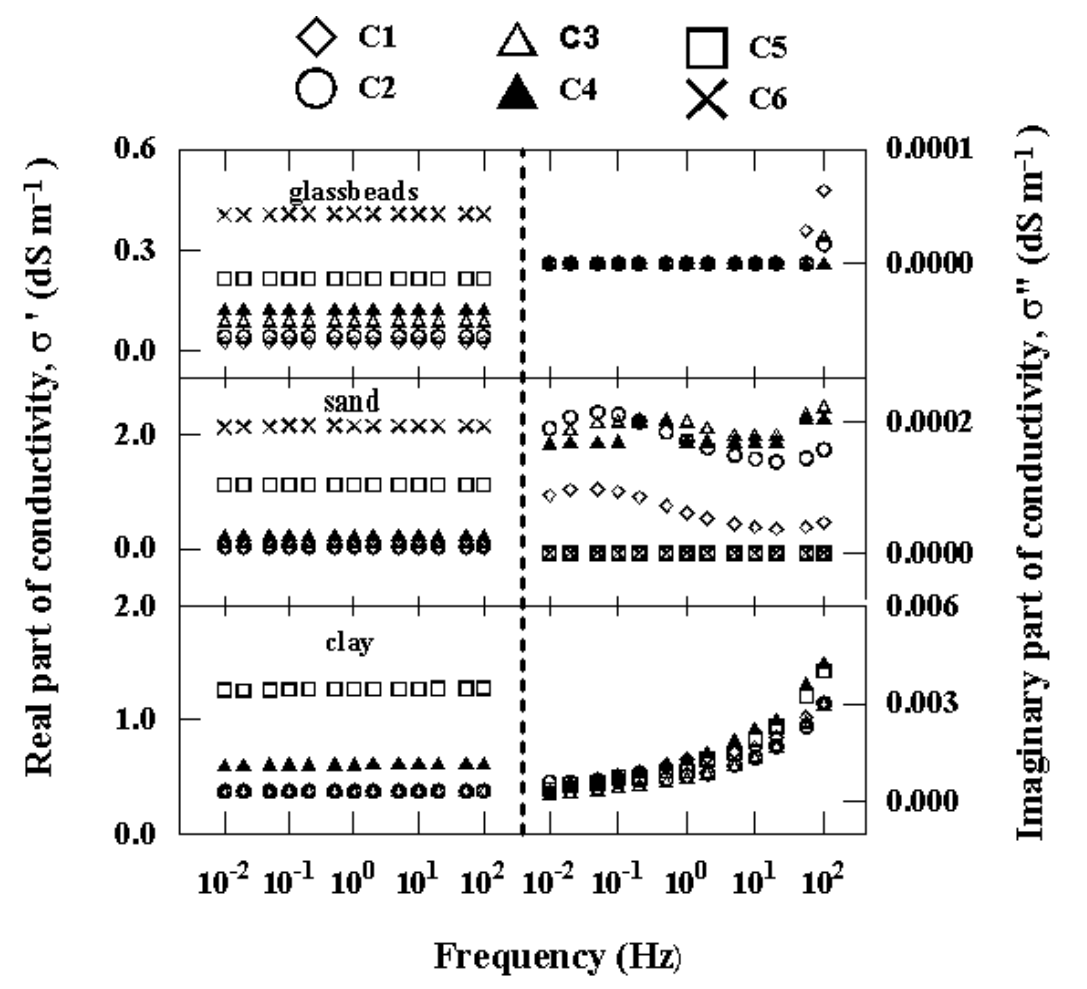

Figure 3b. Variation of real and imaginary parts of electrical conductivity with frequency $(0.01-100 \mathrm{~Hz})$ of the applied voltage in glass beads, sand and clay for different pore-water salt concentrations under saturated condition.

frequency were similar. The magnitude of $\sigma^{\prime \prime}$ was zero except for its few very small values at high frequency for glass beads, and $\leq 2.3 \times 10^{-4} \mathrm{dS} \mathrm{m}^{-1}$ for sand, for pore-water salt concentrations $<0.2 \mathrm{~mol} \mathrm{~L}^{-1}$. The porewater salt concentration $>0.2 \mathrm{~mol} \mathrm{~L}^{-1}$ suppressed the surface electrical conductivity by reducing ionic mobility because of close packing of the counter ions on the mineral surface and reduced $\sigma^{\prime \prime}$ to zero. For clay, $\sigma^{\prime \prime}$ increased with the increase in frequency following power law; the exponent of power law was 0.225 . Since polarization of the Stern layer occurs over $1 \mathrm{mHz}$ to 100 $\mathrm{Hz}$ (Revil et al., 2012) while the Maxwell-Wagner polarization occurs at higher frequencies, usually above $10 \mathrm{~Hz}$ (Chen and Or, 2006), the observed $\sigma^{\prime \prime}$ spectra in clay beyond $10 \mathrm{~Hz}$ was due to superposition of the two polarization mechanisms. Below $10 \mathrm{~Hz}, \sigma^{\prime \prime}$ occurred due to polarization of the Stern layer only. Under very high pore-water concentrations $\left(\mathrm{C}_{10}-\mathrm{C}_{12}\right.$; Table 1$)$, the real part of electrical conductivity dominates, rendering the imaginary part very small. There was a strong dependence of $\sigma^{\prime \prime}$ on the surface electrical conductivity of clay at negligible pore-water salt concentration. Glass beads provided no surface electrical conductivity, sand containing only $1 \%$ (by weight) clay showed only a small effect of surface electrical conduction, but clay resulted in the highest surface electrical conductivity.
So, the imaginary part of electrical conductivity, at low frequency, is a strong function of clay content in a soil, and hence is regarded as an indicator of soil texture (Ghorbani et al., 2008).

\section{Dependency of SIP parameters on pore-water content}

Several distinct features in the variation of phase shift, $\varphi$, of sand and sand-clay mixtures with their pore-water content were observed. As revealed in Figure 4 for the lowest salt concentration of pore water $\left(C_{1}=0.0001\right.$ mol L $\left.\mathrm{L}^{-1}\right), \varphi$ increased with a decrease in pore-water content from 0.33 to $0.19 \mathrm{~m}^{3} \mathrm{~m}^{-3}$ in sand. Since the sand contained only $1 \%$ clay, the contribution of clay to the real part of electrical conductivity was very small; the pore water primarily contributed to this electrical conductivity. Consequently, with the decrease in pore water, the real part of electrical conductivity of sand also decreased (Figure 5) with a resulting increase in $\varphi$. Yoon and Park (2001) also reported that the electrical conductivity of sandy soils depends largely on porewater content and its electrical properties rather than types of the soils. The nature of variation of phase shift in sand over frequency was similar to that for the 


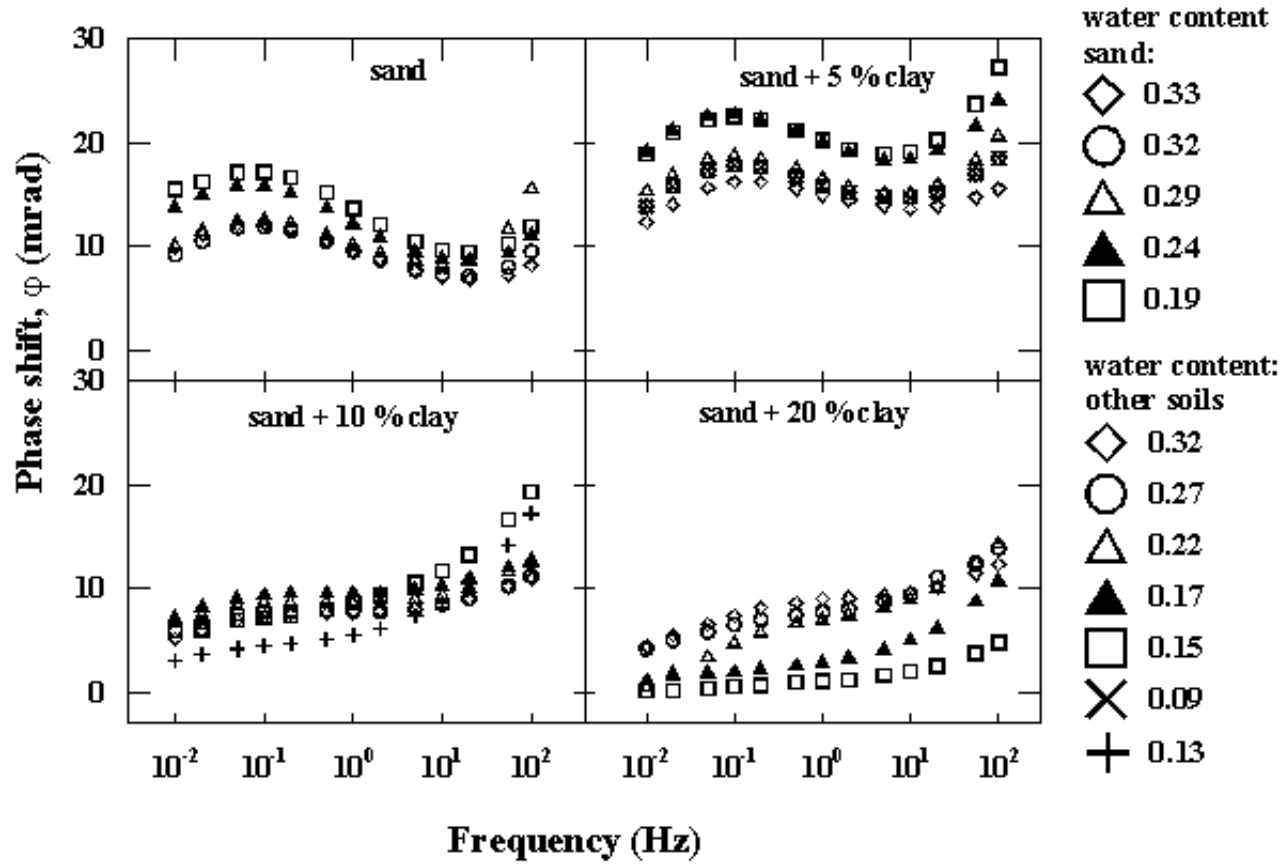

Figure 4. Variation of phase shift with frequency $(0.01-100 \mathrm{~Hz})$ of the applied voltage at different pore-water contents for sand, sand $+5 \%$ clay, sand $+10 \%$ clay and sand $+20 \%$ clay mixture.

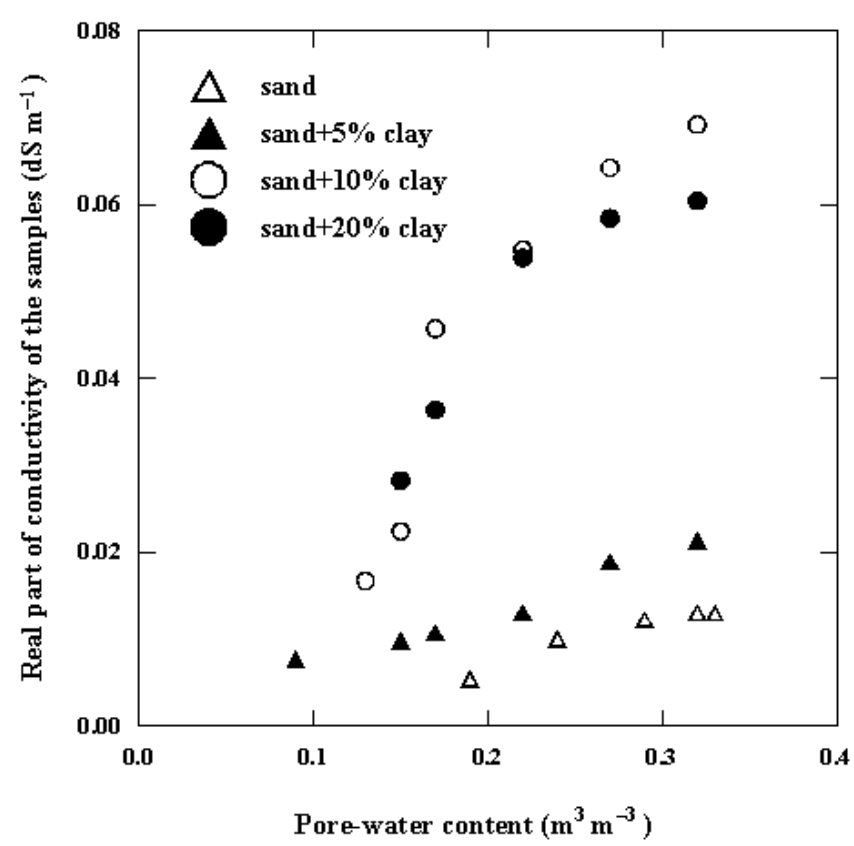

Figure 5. Real part of electrical conductivity of sand, sand $+5 \%$ clay, sand $+10 \%$ clay and sand $+20 \%$ clay mixtures wetted with $0.0001 \mathrm{~mol} \mathrm{~L}^{-1}\left(\mathrm{C}_{1}\right.$; Table 1$) \mathrm{KCl}$ solution obtained at $1 \mathrm{~Hz}$ frequency of the applied voltage as a function of pore-water content.

saturated sand for the two low salt concentrations $\left(\mathrm{C}_{1}\right.$ and $\mathrm{C}_{2}$ ) of pore water (Figure $3 \mathrm{a}$ ), but, as described before, there was an inconsistency in their magnitudes. In sand $+20 \%$ clay mixture, phase shift increased with increasing pore-water content over $0.15-0.32 \mathrm{~m}^{3} \mathrm{~m}^{-3}$; in this sample, the real part of electrical conductivity also increased with increasing pore-water content (Figure 5). The considerable number of clay particles in this sample, compared to sand having only $1 \%$ clay, formed increased number of continuous electrically conductive paths through their EDLs. Actually, the real part of electrical conductivity was very small in the dry state of the sample, but it increased to a maximum value at some large water content, after which the real part of electrical conductivity decreased. At low salt concentration of pore water (e.g., $C_{1}$ ), the EDLs expanded considerably (Mojid and Cho, 2008; their Equation 1) and a large fraction of the current flow occurred through the EDLs, giving rise to a large magnitude of electrical conductivity (Waxman and Smits, 1968). At very small water content, however, the EDLs were very thin and only a few clay particles remained in electrical contact with each other, resulting in small electrical conductivity of the samples (Nye, 1979). The EDLs continued expanding with increasing water content and made more continuous conductive pathways, with a consequent increase in electrical conductivity. Depending on the clay content of the samples, the EDLs expanded fully at some large water content, bringing all clay particles into electrical contact and resulting in the largest electrical conductivity for the samples. The EDLs started dissociating from each 


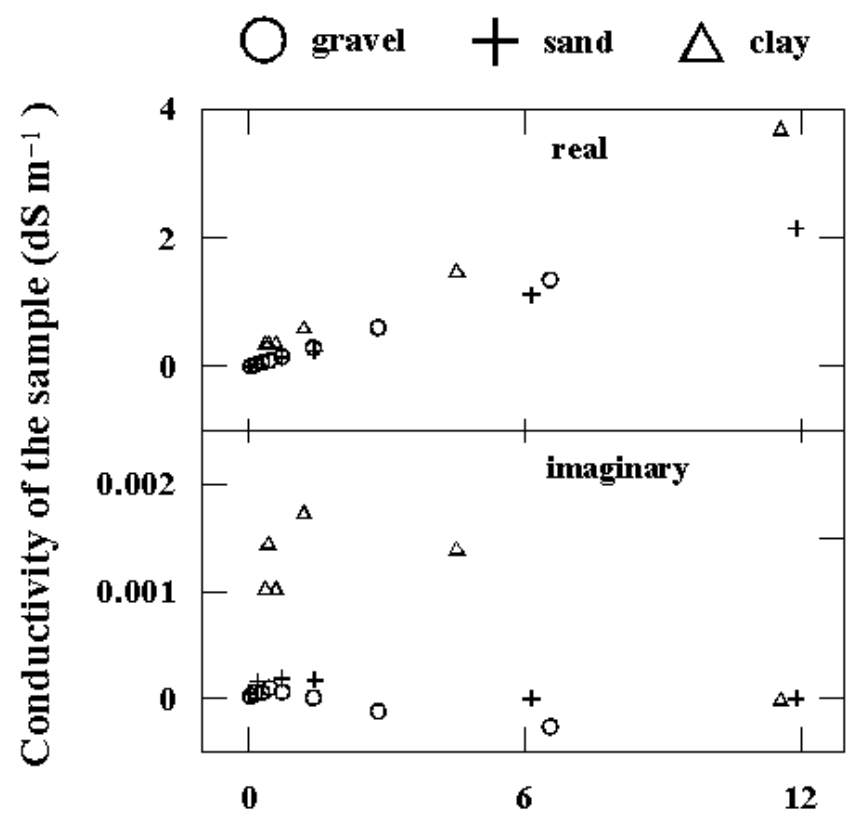

\section{Conductivity of pore water $\left(\mathrm{dS} \mathrm{m}^{-1}\right)$}

Figure 6. Real and imaginary parts of electrical conductivity of gravel, sand and clay obtained at $1 \mathrm{~Hz}$ frequency of the applied voltage as a function of pore-water electrical conductivity.

other as the water content increased further with a consequent decrease in electrical conductivity of the samples (Mojid and Cho, 2006; 2008). As demonstrated by Mojid and Cho (2008; their Figure 2(a-b)) for sand $+30 \%$ clay, a gradual increase in conductive paths with decreasing water content of low salt concentration caused an eventual increase in the real part of electrical conductivity of sand $+20 \%$ clay sample (Figure 5) that was responsible for the decrease in phase shift. Although the phase shift increased for sand and decreased for sand $+20 \%$ clay with increasing porewater content, for the two other sand-clay mixtures (sand $+5 \%$ clay and sand $+10 \%$ clay), $\varphi$ first increased and then decreased with the increase in pore-water content. These results are in conformity with those of Breede et al. (2012; their Figures 4-6) who reported a more complex dependence of the imaginary part of electrical conductivity spectra of the 5, 10 and $20 \%$ sand-clay mixtures on pore-water content. Yoon and Park (2001) also reported significant effect of the amount of fine particles of soils on their electrical properties. Following Lesmes and Morgan (2001) that the relative proportion of grains with a certain size determine the magnitude of imaginary part of electrical conductivity at a particular frequency, Breede et al. (2012) inspected behavior of this electrical conductivity at $10 \mathrm{mHz}$ (for sand fraction) and $1 \mathrm{kHz}$ (for clay fraction according their Equation 5) for the sand-clay mixtures. They found that the imaginary part of electrical conductivity first increased and then decreased with decreasing water content at $10 \mathrm{mHz}$ for all their 280 samples. While at $1 \mathrm{kHz}$, the imaginary part of electrical conductivity at full water saturation increased with increasing clay content for sand-clay mixtures; with decreasing water saturation, this electrical conductivity continuously decreased, at a similar rate, for their three sand-clay mixtures. The phase shift, $\varphi$, for a soil thus varied systematically with its pore-water and clay contents, providing a prospect of correlating them. Another important feature of $\varphi$ in sand and sand $+5 \%$ clay mixture was its wide variation with water content having a distinct peak at $0.1 \mathrm{~Hz}$. This peak in $\varphi$, however, diminished gradually with the increase in clay content in the samples as manifested in Figure 4. Koch et al. (2012) also observed a peak of both the phase and imaginary part of electrical conductivity at frequencies below $10 \mathrm{~Hz}$ for nine samples of different quartz sand (their Figure 6). This low-frequency peak in phase and imaginary part of electrical conductivity was indicative of the SIP relaxation phenomena that they modeled by using a Cole-Cole type model. Breede et al. (2012; their Figures 3-6) also observed a weak maximum of the imaginary part of electrical conductivity in the low-frequency range that indicated a characteristic frequency at about $0.1 \mathrm{~Hz}$ for water saturation (ratio of water content of a sample to its water content at saturation) below $54 \%$; for higher water saturation, they did not observe such a maximum imaginary part of electrical conductivity. The presence of a distinct phase peak, however, implies that the phase shift was strongly sensitive to pore-water content for coarse textured soils at $0.1 \mathrm{~Hz}$.

\section{Low frequency electrical conductivity of gravel, sand and clay}

The employed SIP method showed considerable dispersions of the conductive and capacitive properties of the materials over frequency, especially above $10 \mathrm{~Hz}$ (e.g., Figure 3a). So, following Olhoeft (1985), the effects of pore-water content and pore-water salt concentration on the real and imaginary parts of electrical conductivity of the samples were interpreted over 1 to $10 \mathrm{~Hz}$ to avoid phase errors induced by the measurement system. Figure 6 illustrates variation of the real part, $\sigma^{\prime}$, and imaginary part, $\sigma^{\prime \prime}$, of electrical conductivity of gravel, sand and clay obtained at $1 \mathrm{~Hz}$ with their pore-water electrical conductivity. The material-specific strong linear relationship $\left(r^{2}=0.999\right.$ for all three materials) obtained between the real part of electrical conductivity and pore-water electrical conductivity reaffirmed that $\sigma^{\prime}$ was an exclusive function of pore-water electrical conductivity. Due to significant contribution of surface electrical conductivity, clay provided higher $\sigma^{\prime}$ than that provided by gravel and 


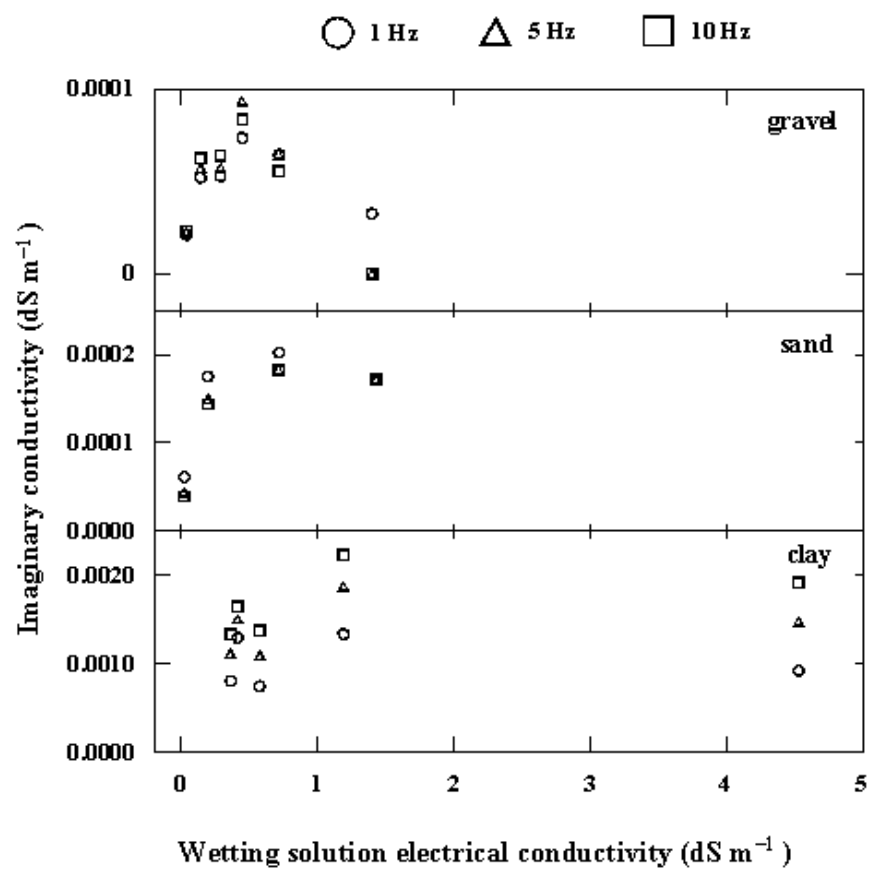

Figure 7. Variation of the imaginary part of electrical conductivity of gravel, sand and clay obtained at 1, 5 and 10 $\mathrm{Hz}$ frequency of the applied voltage with electrical conductivity of the wetting solutions.

sand. Note that, at high pore-water content with low salinity (e.g., $C_{1}$ ), clay provided low real part of electrical conductivity (Figure 5) since the number of electrically conductive pathways decreased at high pore-water content with low salinity. The imaginary part of electrical conductivity of gravel was smaller than that of sand, and $\sigma^{\prime \prime}$ for sand was much smaller than that of clay. The variation of imaginary part of electrical conductivity with electrical conductivity of the wetting solutions was compared for 1,5 and $10 \mathrm{~Hz}$ in Figure 7 for the three materials. As reported by Revil and Glover (1997), the imaginary part of electrical conductivity of the materials increased over low pore-water electrical conductivity but decreased over higher conductivities. The variations in $\sigma^{\prime \prime}$ of the gravel, sand and clay were attributed to the pore-water salinity dependence of the specific surface electrical conductivity contribution associated with the Stern layer (Revil and Florsch, 2010). Slater and Lesmes (2002) showed that $\sigma^{\prime \prime}$ did not change with pore-water salt concentration $>0.02 \mathrm{~mol} \mathrm{~L}^{-1}$; below this salinity, $\sigma^{\prime \prime}$ decreased with the decrease in salinity level. The initial increase of $\sigma^{\prime \prime}$ over low pore-water electrical conductivity of our samples (up to $0.5 \mathrm{dS} \mathrm{m}^{-1}$ for both gravel and sand, and $1.5 \mathrm{dS} \mathrm{m}^{-1}$ for clay; Figure 6) was due to increased polarization conductivity of the EDLs and enhanced electrical contact among the EDLs with increasing pore-water electrical conductivity up to the threshold values. The thickness of EDLs decreased with increasing pore-water electrical conductivity. Consequently, the polarization conductivity that resulted in imaginary part of electrical conductivity also decreased since mobility of the ions decreased in the suppressed EDLs at higher pore-water electrical conductivities.

Both the real and imaginary parts of electrical conductivity of sand and sand-clay mixtures increased, following power law, with the increase in pore-water content of different salt concentrations, except for sand in which the imaginary part of electrical conductivity remained unchanged. These behaviors of the real and imaginary parts of electrical conductivity obtained at 1 $\mathrm{Hz}$ frequency of the applied voltage are demonstrated in Figure 8, for an example, for sand and sand+20\% clay. Figure 9 compares variation of the imaginary part of electrical conductivity of sand and three sand-clay mixtures obtained at $1 \mathrm{~Hz}$ with pore-water content of concentration $\mathrm{C}_{1}$. The $1-\mathrm{Hz}$ frequency was chosen since the real part of electrical conductivity varied only marginally over low frequency $(<1 \mathrm{kHz})$, and we focused on low frequencies because of our interest in the interpretation of IP data sets that are recorded in the field measurements at low frequencies. Therefore, the real and imaginary parts of electrical conductivity in Figures 8 and 9 are exemplarily shown at $1 \mathrm{~Hz}$ as a function of pore-water content of the samples.

Figure 10 demonstrates variation of the ratio of real part of electrical conductivity of unsaturated sand and sand-clay mixtures obtained at $1 \mathrm{~Hz}$ to that of their saturated states with the degree of pore-water saturation of the materials; the salt concentrations of pore-water were $C_{1}, C_{3}$ and $C_{5}$ (Table 1). The electrical conductivity ratio of the materials increased with the increasing degree of water saturation. The relationship between the electrical conductivity ratio and degree of pore-water saturation was linear, except for the sand $+20 \%$ clay mixture, for which the real part of electrical conductivity ratio first increased linearly and then leveled off at water saturation level $>0.6$ (Figure 10). This was because, in this high clay-containing sample, the contribution of clay particles to the real part of electrical conductivity was small at low pore-water content but increased rapidly as the outer (beyond Stern layer) bulk water layer (of considerable salt concentration) developed at higher pore-water contents around the particles. Similar to the finding of Saarenketo (1998), a clear jump in the real part of electrical conductivity in sand $+20 \%$ clay mixture (Figure 10) took place when the unbound free water (at saturation level 0.2) started to fill the pores among the mineral grains. This implied that the effect of hydrated clays on electrical conductivity of a soil was significant, as was also reported by Logsdon and Laird (2004), and must be considered separately for clay soils.

For the sand and sand $+5 \%$ clay, a single linear relation $\left(r^{2}=0.963\right)$ with a slope of 1.131 and intercept 


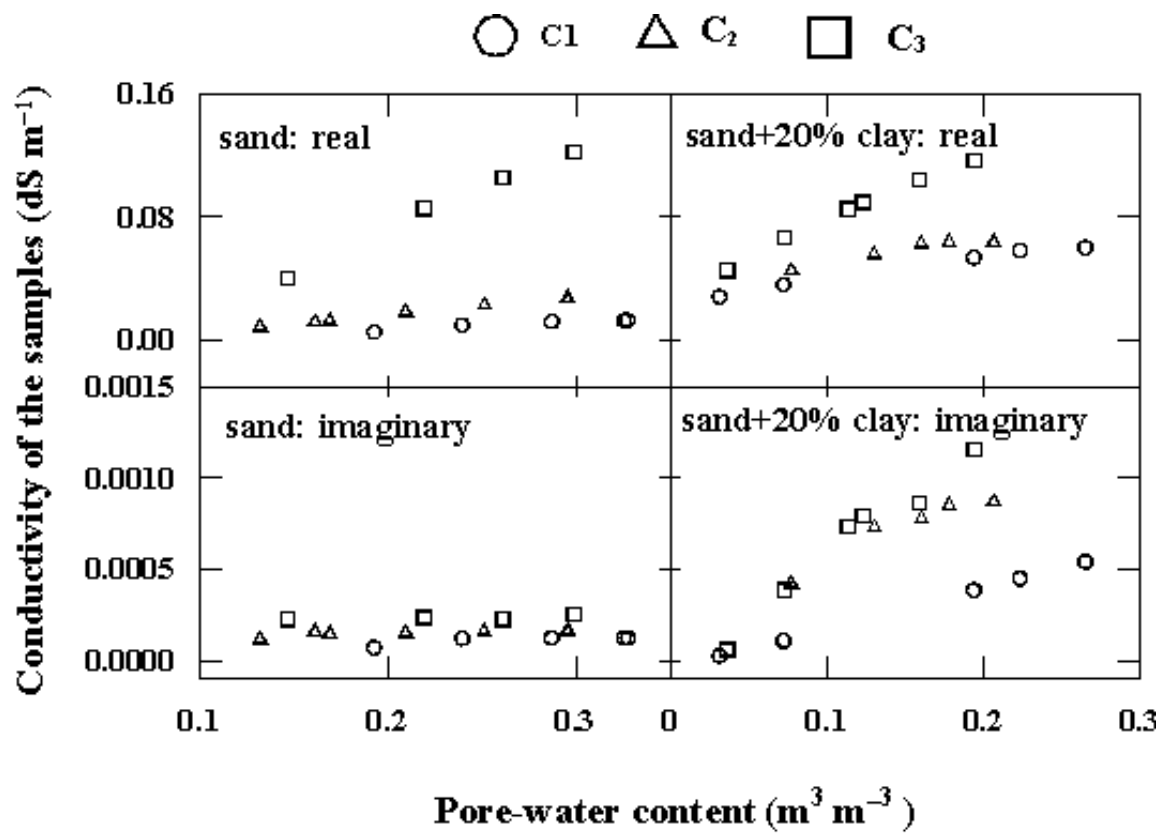

Figure 8. Real and imaginary parts of electrical conductivity of sand and sand $+20 \%$ clay mixture obtained at $1 \mathrm{~Hz}$ frequency of the applied voltage as affected by porewater content of the samples for three different pore-water salt concentrations $\left(\mathrm{C}_{1}\right.$, $\mathrm{C}_{2}, \mathrm{C}_{3}$; Table 1).

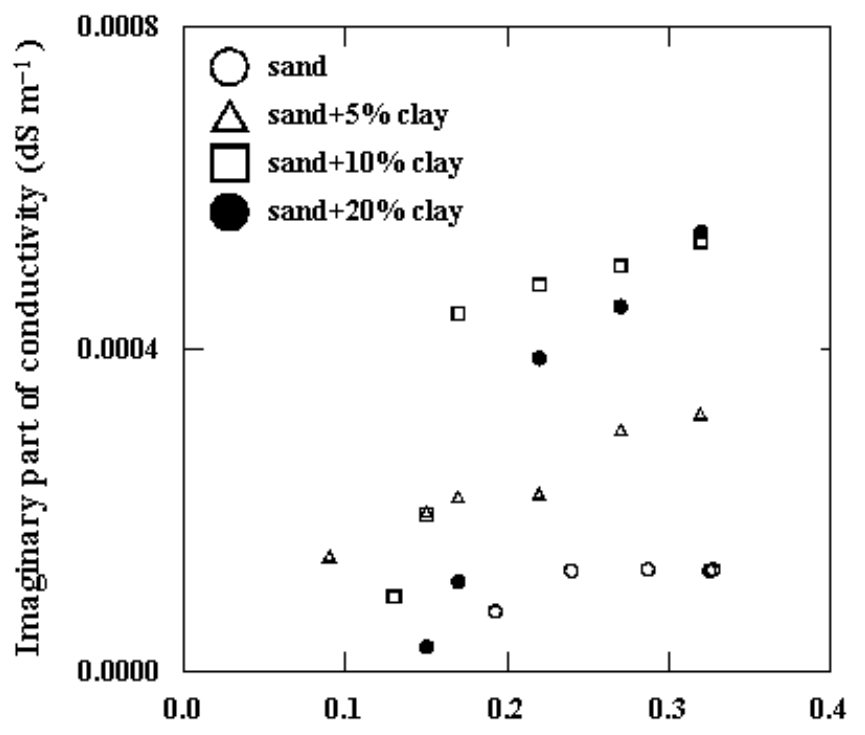

Pore-water content $\left(\mathrm{m}^{3} \mathrm{~m}^{-3}\right)$

Figure 9. Imaginary part of electrical conductivity of sand, sand $+5 \%$ clay, sand $+10 \%$ clay and sand $+20 \%$ clay mixtures wetted with $0.0001 \mathrm{~mol} \mathrm{~L}^{-1}\left(\mathrm{C}_{1}\right.$; Table 1$) \mathrm{KCl}$ solution obtained at $1 \mathrm{~Hz}$ frequency of the applied voltage as a function of porewater content.

of -0.051 governed the relationship between the real part of electrical conductivity ratio and degree of porewater saturation. At any given degree of pore-water saturation, the real part of electrical conductivity ratio was higher in the high clay-containing samples than in the low clay-containing samples. These observations revealed that the real part of electrical conductivity ratio versus the degree of pore-water saturation relationship was soil specific for high clay-containing soils but unique for quartz sand and low $(\leq 5 \%)$ clay-containing soils. Similar to the real part of electrical conductivity ratio, the imaginary part of electrical conductivity ratio of the materials obtained at $1 \mathrm{~Hz}$ also increased with the increasing degree of pore-water saturation as illustrated in Figure 11 for three wetting solution concentrations $\left(\mathrm{C}_{1}, \mathrm{C}_{2}\right.$ and $\left.\mathrm{C}_{3}\right)$. For sand, variation of this conductivity ratio with pore-water saturation was very small. In sand and sand $+10 \%$ clay, there was no variation in the imaginary part of electrical conductivity ratio among the three pore-water concentrations. The other two samples showed some variations, which, however, appeared non-systematic. Fitting the imaginary part of electrical conductivity ratio versus the degree of pore-water saturation of the four samples together provided a logarithmic fitting function with a coefficient of determination of $r^{2}=0.88$. Since the variation of imaginary part of electrical conductivity ratio with porewater saturation was very small for sand, the logarithmic fitting of the two variables improved $\left(r^{2}=\right.$ 0.91 ) when data of only the other three samples were fitted. 


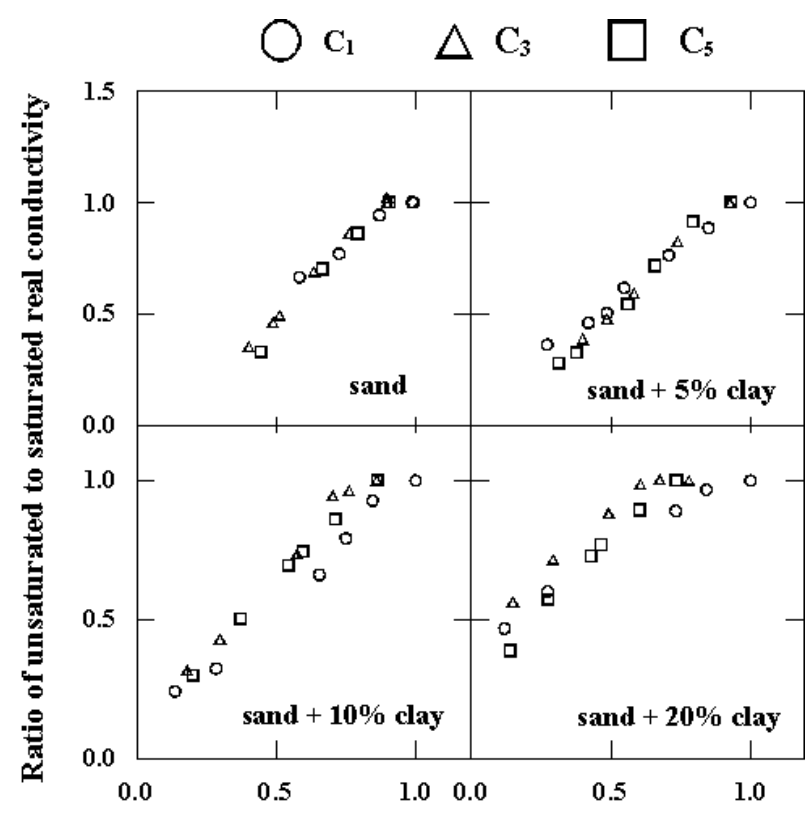

Degree of pore-water saturation

Figure 10. Variation of the ratio of real part of electrical conductivity of unsaturated to saturated sand, sand $+5 \%$ clay, sand $+10 \%$ clay and sand $+20 \%$ clay mixtures obtained at $1 \mathrm{~Hz}$ frequency of the applied voltage over the degree of porewater saturation of the samples for three different pore-water salt concentrations $\left(\mathrm{C}_{1}, \mathrm{C}_{3}, \mathrm{C}_{5}\right.$; Table 1$)$.

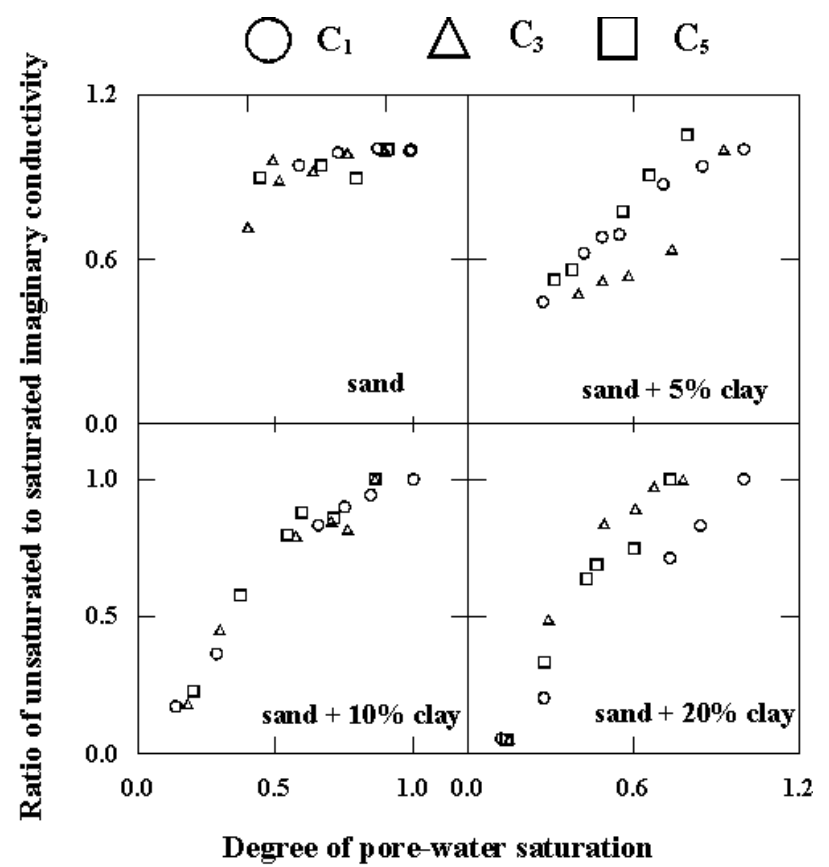

Figure 11. Variation of the ratio of imaginary part of electrical conductivity of unsaturated to saturated sand, sand $+5 \%$ clay, sand $+10 \%$ clay and sand $+20 \%$ clay mixtures obtained at $1 \mathrm{~Hz}$ frequency of the applied voltage over the degree of porewater saturation of the samples for three different pore-water salt concentrations $\left(\mathrm{C}_{1}, \mathrm{C}_{3}, \mathrm{C}_{5}\right.$; Table 1$)$.

\section{Conclusions}

The frequency-dependent phase shift of glass beads, sand and clay arising from the polarizations of electrical double layers and pore-water decreased with the increase in pore-water salt concentration, and effectively diminished above a material-specific limiting salt concentration. The evidence of a three times larger imaginary part of electrical conductivity of sand than that of gravel, and a much larger imaginary part of electrical conductivity of clay than that of sand would allow developing functional relationship(s) between this electrical conductivity and soil mineral constituent(s). The imaginary part of electrical conductivity would therefore serve as an indicator of soil texture. The textural discrimination of sub-surface by means of the imaginary part of electrical conductivity also has a potential to identify and locate aquifers. The observed high sensitivity of the phase shift of gravel and sand to pore-water content at $0.1 \mathrm{~Hz}$ exposed a possibility of correlating these two variables for coarse texture soils, and thus providing a means to monitor soil-water content. The observed power law variation of electrical conductivity (both real and imaginary) of sand and sand-clay mixtures for different pore-water salt concentrations with pore-water content also has such a prospect. The ratio of the real and imaginary parts of electrical conductivity of the unsaturated to saturated sand and sand-clay mixtures increased linearly with the increasing degree of pore-water saturation except for sand $+20 \%$ clay mixture, in which the real part of electrical conductivity ratio first increased linearly and then levelled off at high (0.6) pore-water saturation. For sand and sand $+5 \%$ clay, a unique linear relation governed the real part of electrical conductivity ratio versus degree of pore-water saturation relationship. It therefore led to speculate that the real part of electrical conductivity ratio versus the degree of pore-water saturation relationship would be material specific for fine texture soils but unique for coarse texture soils. Such relationships of electrical conductivity of soils to their pore-water saturation, after establishing functionally, would provide predictive values of solute content of soils that are required for saline/polluted soil management, calculation of leaching requirements, planning land reclamation and groundwater pollution control.

\section{REFERENCES}

Attwa, M., \& Günther, T. (2013). Spectral induced polarization measurements for predicting the hydraulic conductivity in sandy aquifers. Hydrology and Earth System Sciences, 17(10), 4079-4094. 
Banton, O., Seguin, M. K., \& Cimon, M. A. (1997). Mapping field scale physical properties of soil with electrical resistivity. Soil Science Society of America Journal, 61(4), 1010-1017.

Binley, A., \& Kemna, A. (2005). DC resistivity and induced polarization methods. In Hydrogeophysics (pp. 129-156). Springer, The Netherlands.

Binley, A., Slater, L., Fukes, M., \& Cassiani, G. (2005). The relationship between spectral induced polarization and hydraulic properties of saturated and unsaturated sandstone. Water Resources Research, 41(12), 13p.

Boadu, F. K., \& Seabrook, B. (2000). Estimating hydraulic conductivity and porosity of soils from spectral electrical response measurements. Journal of Environmental and Engineering Geophysics, 5(4), 1-9.

Börner, F. D., Schopper, J. R., \& Weller, A. (1996). Evaluation of transport and storage properties in the soil and groundwater zone from induced polarization measurements. Geophysical Prospecting, 44(4), 583-601.

Börner, F., Gruhne, M., \& Schön, J. (1993). Contamination indications derived from electrical properties in the low frequency range. Geophysical Prospecting, 41(1), 83-98.

Breede, K., \& Kemna, A. (2012). Spectral induced polarization measurements on variably saturated sand-clay mixtures. Near Surface Geophysics, 10(6), 479-489.

Cahyna, F., Mazac, O., \& Venhodova, D, (1990). Determination of the extent of cyanide contamination by surface geoelectrical methods. Geotechnical and Environmental Geophysics, 2, 97-99.

Chen, Y., \& Or, D. (2006). Effects of Maxwell-Wagner polarization on soil complex dielectric permittivity under variable temperature and electrical conductivity. Water Resources Research, 42(6), 14p.

Cosenza, P., Ghorbani, A., Revil, A., Zamora, M., Schmutz, M., Jougnot, D., \& Florsch, N. (2008). A physical model of the low-frequency electrical polarization of clay-rocks. Journal of Geophysical Research: Solid Earth (1978-2012), 113(B8).

de Lima, O. A. L., \& Sharma, M. M. (1992). A generalized Maxwell-Wagner theory for membrane polarization in shaly sands. Geophysics, 57(3), 431-440.

Fixman, M. (1980). Charged macromolecules in external fields. I. The sphere. The Journal of Chemical Physics, 72(9), 5177-5186.

Ghorbani, A., Cosenza, P., Revil, A., Zamora, M., Schmutz, M., Florsch, N., \& Jougnot, D. (2009). Non-invasive monitoring of water content and textural changes in clayrocks using spectral induced polarization: A laboratory investigation. Applied Clay Science, 43(3), 493-502.

Grunat, D. A., Slater, L. D., \& Wehrer, M. (2013). Complex electrical measurements on an undisturbed soil core: evidence for improved estimation of saturation degree from imaginary conductivity. Vadose Zone Journal, 12(4), doi:10.2136/vzj2013.03.0059.

Hördt, A., Blaschek, R., Kemna, A., \& Zisser, N. (2007). Hydraulic conductivity estimation from induced polarization data at the field scale - the Krauthausen case history. Journal of Applied Geophysics, 62(1), 33-46.

Jougnot, D., Ghorbani, A., Revil, A., Leroy, P., \& Cosenza, P. (2010). Spectral induced polarization of partially saturated clay-rocks: a mechanistic approach. Geophysical Journal International, 180(1), 210-224.
Kearey, P., Brooks, M., \& Hill, I. (2013). An introduction to geophysical exploration. John Wiley \& Sons.

Kemna, A., Binley, A., Cassiani, G., Niederleithinger, E., Revil, A., Slater, L., \& Zimmermann, E. (2012). An overview of the spectral induced polarization method for near-surface applications. Near Surface Geophysics, 10(6), 453-468.

Kemna, A., Münch, H-M., Titov, K., Zimmermann, E., \& Vereecken, H. (2005). Relation of SIP relaxation time of sands to salinity, grain size and hydraulic conductivity: Extended Abstracts: Near Surface 2005 - 11th European Meeting of Environmental and Engineering Geophysics, 4p.

Klein, J. D., \& Sill, W. R. (1982). Electrical properties of artificial clay-bearing sandstone. Geophysics, 47(11), 15931605.

Knight, R. J., Endres, A. (1990). A new concept in modeling the dielectric response of sand stones: Defining a wetted rock and bulk water system. Geophysics, 55(5), 586-594.

Koch, K., Kemna, A., Irving, J., \& Holliger, K. (2011). Impact of changes in grain size and pore space on the hydraulic conductivity and spectral induced polarization response of sand. Hydrology and Earth System Sciences, 15(6), 17851794.

Koch, K., Revil, A., \& Holliger, K. (2012). Relating the permeability of quartz sands to their grain size and spectral induced polarization characteristics. Geophysical Journal International, 190(1), 230-242.

Leroy, P., \& Revil. A. (2004). A triple-layer model of the surface electrochemical properties of clay minerals. Journal of Colloid and Interface Science, 270, 371-380.

Leroy, P., \& Revil, A. (2009). A mechanistic model for the spectral induced polarization of clay material. Journal of Geophysical Research: Solid Earth, 114(B10), 21p.

Leroy, P., Revil, A., Kemna, A., Cosenza, P., \& Ghorbani, A. (2008). Complex conductivity of water-saturated packs of glass beads. Journal of Colloid and Interface Science, 321(1), 103-117.

Lesmes, D. P., \& Frye, K. M. (2001). Influence of pore fluid chemistry on the complex conductivity and induced polarization responses of Berea Sandstone. Journal of Geophysical Research: Solid Earth, 106(B3), 4079-4090.

Logsdon, S. D., \& Laird, D. A. (2004). Electrical conductivity of smectites as influenced by saturating cation and humidity. Clays and Clay Minerals, 52(4), 411-420.

Mojid, M. A., \& Cho, H. (2006). Estimating the fully developed diffuse double layer thickness from the bulk electrical conductivity in clay. Applied Clay Science, 33(3), 278-286.

Mojid, M. A., \& Cho, H. (2008). Wetting solution and electrical double layer contributions to bulk electrical conductivity of sand-clay mixtures. Vadose Zone Journal, 7(3), 972-980.

Mojid, M. A., Cho, H., \& Miyamoto, H. (2012). Evaluation of a Lock-in-Amplifier-based spectral induced polarization method for soil characterization. Environmental Control in Biology, 50(4), 363-374.

Nye, P. H. (1979). Diffusion of ions and uncharged solutes in soils and soil clays. Advances in Agronomy.

Ogilvy, A. A., Kuzmina, E. N. (1972). Hydrogeologic and engineering-geologic possibilities for employing the method of induced potentials. Geophysics, 37(5), 839-861. Okay, G., Leroy, P., Ghorbani, A., Cosenza, P., Camerlynck, C., Cabrera, J., \& Revil, A. (2014). Spectral induced polarization of clay-sand mixtures: Experiments and modeling. Geophysics, 79(6), E353-E375.

Olhoeft, G. R. (1985). Low-frequency electrical properties. 
Geophysics, 50(12), 2492-2503.

Personna, Y. R., Slater, L., Ntarlagiannis, D., Werkema, D., \& Szabo, Z. (2013). Complex resistivity signatures of ethanol in sand-clay mixtures. Journal of Contaminant Hydrology, 149, 76-87.

Revil, A. (1999). Ionic diffusivity, electrical conductivity, membrane and thermoelectric potentials in colloids and granular porous media: A unified model. Journal of Colloid and Interface Science, 212(2), 503-522.

Revil, A. (2012). Spectral induced polarization of shaly sands: Influence of the electrical double layer. Water Resources Research, 48(2), W02517.

Revil, A. (2013). Effective conductivity and permittivity of unsaturated porous materials in the frequency range 1 mHz-1GHz. Water Resources Research, 49(1), 306-327.

Revil, A., \& Florsch, N. (2010). Determination of permeability from spectral induced polarization in granular media. Geophysical Journal International, 181(3), 1480-1498.

Revil, A., Glover, P. W. J. (1997). Theory of ionic-surface electrical conduction in porous media. Physical Review B, 55(3), 1757.

Revil, A., Koch, K., \& Holliger, K. (2012). Is it the grain size or the characteristic pore size that controls the induced polarization relaxation time of clean sands and sandstones?. Water Resources Research, 48(5), W05602. doi: 10.1029/2011WR011561.

Saarenketo, T. (1998). Electrical properties of water in clay and silty soils. Journal of Applied Geophysics, 40(1), 73-88.

Sadowski, R. M. (1988). Clay-organic interactions: M.Sc. Thesis, Dept. of Geochemistry, Colo. School of Mines, Golden, CO, 209p.

Samouëlian, A., Cousin, I., Tabbagh, A., Bruand, A., \& Richard, G. (2005). Electrical resistivity survey in soil science: a review. Soil and Tillage research, 83(2), 173-193.

Schwartz, N., \& Furman, A. (2015). On the spectral induced polarization signature of soil organic matter. Geophysical Journal International, 200(1), 589-595.

Schwarz, G. (1962). A theory of the low-frequency dielectric dispersion of colloidal particles in electrolyte solution 1, 2 . The Journal of Physical Chemistry, 66(12), 2636-264.

Scollar, I., Tabbagh, A., Hesse, A., Herzog, I. (1990). Archaeological prospecting and remote sensing, Cambridge University Press, 674p.

Scott, J. B., \& Barker, R. D. (2003). Determining pore-throat size in Permo-Triassic sandstones from low-frequency electrical spectroscopy. Geophysical Research Letters, 30(9).

Slater, L., Lesmes, D. (2002). Electrical-hydraulic relationships observed for unconsolidated sediments. Water Resources Research, 38(10), 31p.

Slater, L., Ntarlagiannis, D., \& Wishart, De. (2006). On the relationship between induced polarization and surface area in metal-sand and clay-sand mixtures. Geophysics, 71(2), A1-A5.

Stern, O. (1924). Zur Theorie der elektrolytischen Doppelschicht. Zeitschrift für Elektrochemie und Angewandte Physikalische Chemie, 30(21-22), 508-516.

Sturrock, J. T. (1999). Estimates of permeability from broadband (spectral) induced polarization measurements, M. S. thesis, Boston College, Chestnut Hill, Mass.

Sumner, J. S. (2012). Principles of induced polarization for geophysical exploration (Vol. 5). Elsevier.
Tong, M., Li, L., Wang, W., \& Jiang, Y. (2006). A time-domain induced polarization method for estimating permeability in a shaly sand reservoir. Geophysical Prospecting, 54(5), 623631.

Ulrich, C., \& Slater, L. (2004). Spectral-induced polarization measurements on unsaturated unconsolidated sediments. Geophysics, 69(3), 762-771.

Ustra, A., Slater, L., Ntarlagiannis, D., \& Elis, V. (2012). Spectral induced polarization (SIP) signatures of clayey soils containing toluene. Near Surface Geophysics, 10(6), 503-515.

Vanhala, H., \& Soininen, H. (1995). Laboratory technique for measurement of spectral induced polarization response of soil samples. Geophysical Prospecting, 43(5), 655-676.

Vinegar, H. J., \& Waxman, M. H. (1984). Induced polarization of shaly sands. Geophysics, 49(8), 1267-1287.

Society of Exploration Geophysicists (SEG). (1990). Geotechnical and environmental geophysics (Vol. 1, Pp. 147-189). Ward, S. H. (Ed.). Tulsa, Oklahoma: Society of Exploration Geophysicists.

Waxman, M. H., \& Smits, L. J. M. (1968). Electrical conductivities in oil-bearing shaly sands. Society of Petroleum Engineers Journal, 8(2), 107-122.

Weller, A., \& Börner, F. D. (1996). Measurements of spectral induced polarization for environmental purposes. Environmental Geology, 27(4), 329-334.

Weller, A., Nordsiek, S., \& Debschütz, W. (2010a). Estimating permeability of sandstone samples by nuclear magnetic resonance and spectral-induced polarization. Geophysics, 75(6), E215-E226.

Weller, A., Seichter, M., \& Kampke, A. (1996). Inducedpolarization modelling using complex electrical conductivities. Geophysical Journal International, 127(2), 387-398.

Weller, A., \& Slater, L. (2012). Salinity dependence of complex conductivity of unconsolidated and consolidated materials: Comparisons with electrical double layer models. Geophysics, 77(5), D185-D198.

Weller, A., Slater, L., Huisman, J. A., Esser, O., \& Haegel, F. $\mathrm{H}$. (2015). On the specific polarizability of sands and sandclay mixtures. Geophysics, 80(3), A57-A61.

Weller, A., Slater, L., \& Nordsiek, S. (2013). On the relationship between induced polarization and surface conductivity: Implications for petrophysical interpretation of electrical measurements. Geophysics, 78(5), D315-D325.

Weller, A., Slater, L., Nordsiek, S., \& Ntarlagiannis, D. (2010b). On the estimation of specific surface per unit pore volume from induced polarization: A robust empirical relation fits multiple data sets. Geophysics, 75(4), WA105-WA112.

Yoon, G. L., \& Park, J. B. (2001). Sensitivity of leachate and fine contents on electrical resistivity variations of sandy soils. Journal of Hazardous Materials, 84(2), 147-161.

Zimmermann, E., Kemna, A., Berwix, J., Glaas, W., Münch, H-M., \& Huisman, J. A. (2008). A high-accuracy impedance spectrometer for measuring sediments with low polarizability. Measurement Science and Technology, 19(10), 105603, doi:10.1088/0957-0233/19/10/105603.

Zisser, N., Kemna, A., \& Nover, G. (2010). Relationship between low-frequency electrical properties and hydraulic permeability of low-permeability sandstones. Geophysics, 75(3), 75, E131-E141. 